\title{
Exploring the venom of the forest cobra snake: Toxicovenomics and antivenom profiling of Naja melanoleuca
}

\author{
Lauridsen, Line P.; Laustsen, Andreas Hougaard; Lomonte, Bruno; Gutiérrez, José María
}

Published in:

Journal of Proteomics

Link to article, DOI:

10.1016/j.jprot.2016.08.024

Publication date:

2017

Document Version

Peer reviewed version

Link back to DTU Orbit

Citation (APA):

Lauridsen, L. P., Laustsen, A. H., Lomonte, B., \& Gutiérrez, J. M. (2017). Exploring the venom of the forest cobra snake: Toxicovenomics and antivenom profiling of Naja melanoleuca. Journal of Proteomics, 150, 98-108. https://doi.org/10.1016/j.jprot.2016.08.024

\section{General rights}

Copyright and moral rights for the publications made accessible in the public portal are retained by the authors and/or other copyright owners and it is a condition of accessing publications that users recognise and abide by the legal requirements associated with these rights.

- Users may download and print one copy of any publication from the public portal for the purpose of private study or research.

- You may not further distribute the material or use it for any profit-making activity or commercial gain

- You may freely distribute the URL identifying the publication in the public portal 
Exploring the venom of the forest cobra snake: Toxicovenomics and antivenom profiling of Naja melanoleuca

Line P. Lauridsen ${ }^{1}$, Andreas H. Laustsen ${ }^{1,2}$, Bruno Lomonte ${ }^{3}$, José María Gutiérrez ${ }^{3}$

${ }^{1}$ Department of Biotechnology and Biomedicine, Technical University of Denmark,

Denmark

${ }^{2}$ Department of Drug Design and Pharmacology, Faculty of Health and Medical

Sciences, University of Copenhagen, Denmark

${ }^{3}$ Instituto Clodomiro Picado, Facultad de Microbiología, Universidad de Costa Rica, San José, Costa Rica

Running title: Toxicovenomics of forest cobra venom

Keywords: Naja melanoleuca; forest cobra; snake venom; proteomics; toxicovenomics; antivenoms

Address for correspondence:

\author{
José María Gutiérrez \\ Instituto Clodomiro Picado \\ Facultad de Microbiología \\ Universidad de Costa Rica \\ San José, COSTA RICA \\ jose.gutierrez@ucr.ac.cr
}




\begin{abstract}
A toxicovenomic analysis of the venom of the forest cobra, N. melanoleuca, was performed, revealing the presence of a total of 52 proteins by proteomics analysis. The most abundant proteins belong to the three-finger toxins (3FTx) (57.1 w\%), which includes post-synaptically acting $\alpha$-neurotoxins. Phospholipases $\mathrm{A}_{2}$ $\left(\mathrm{PLA}_{2}\right)$ were the second most abundant group of proteins $(12.9 \mathrm{w} \%)$, followed by metalloproteinases (SVMPs) (9.7 w\%), cysteine-rich secretory proteins (CRISPs) (7.6 $\mathrm{w} \%$ ), and Kunitz-type serine proteinase inhibitors (3.8 w\%). A number of additional protein families comprised each less than $3 \mathrm{w} \%$ of venom proteins. A toxicity screening of the fractions, using the mouse lethality test, identified toxicity in RPHPLC peaks 3, 4, 5 and 8 , all of them containing $\alpha$-neurotoxins of the 3FTx family, whereas the rest of the fractions did not show toxicity at a dose of $0.53 \mathrm{mg} / \mathrm{kg}$. Three polyspecific antivenoms manufactured in South Africa and India were tested for their immunoreactivity against crude venom and fractions of $N$. melanoleuca. Overall, antivenoms immunorecognized all fractions in the venom, the South African antivenom showing a higher titer against the neurotoxin-containing fractions. This toxicovenomic study identified the 3FTx group of $\alpha$-neurotoxins in the venom of $N$. melanoleuca as the relevant targets to be neutralized.
\end{abstract}

(200 words) 


\section{Biological significance}

A toxicovenomic analysis of the venom of the forest cobra, also known as black cobra, Naja melanoleuca, was performed. Envenomings by this elapid species are characterized by a progressive descending paralysis which starts with palpebral ptosis and, in severe cases, ends up with respiratory arrest and death. A total of 52 different proteins were identified in this venom. The most abundant protein family was the three-finger toxin (3FTx) family, which comprises almost $57.1 \mathrm{w} \%$ of the venom, followed by phospholipases $\mathrm{A}_{2}\left(\mathrm{PLA}_{2}\right)(12.9 \mathrm{w} \%)$. In addition, several other protein families were identified in a much lower percentage in the venom. A toxicity screening of the fractions, using the mouse lethality assay, identified four peaks as those having toxicity higher than that of the crude venom. These fractions predominantly contain $\alpha$-neurotoxins of the 3FTx family. This toxicovenomic characterization agrees with the clinical and experimental manifestations of envenomings by this species, in which a strong neurotoxic effect predominates. Therefore, our findings suggest that immunotherapy against envenomings by $N$. melanoleuca should be directed towards the neutralization of 3FTxs; this has implications for the improvement of current antivenoms and for the development of novel antivenoms based on biotechnological approaches. A screening of the immunoreactivity of three antivenoms being distributed in sub-Saharan Africa revealed that they immunoreact with the fractions containing $\alpha$-neurotoxins, although with different antibody titers. 


\section{Introduction}

The forest cobra, also known as the black cobra (Naja melanoleuca), is a highly venomous member of the elapid snake family, reaching up to 3.1 meters in length, and being able to deliver venom yields above 1 gram per milking [1]. $N$. melanoleuca is the largest of the African cobra species and it is known to inhabit moist river areas, primary and secondary forests, and suburban habitats in Western, Central, and Southern Africa [2-4]. Its coloration may vary between three different color morphs, and it is active during the day, where it feeds on mammals, frogs, and fish $[2,3]$. From the clinical standpoint, envenomings by $N$. melanoleuca have been classified within the syndromic category 3, characterized by progressive paralysis (neurotoxicity) [5]. Patients develop a descending progressive paralysis which starts with ptosis, external ophtalmoplegia and weakness of muscles innervated by the cranial nerves, with patients having difficulties in swallowing and speaking. Eventually the respiratory muscles become paralyzed, and death ensues unless mechanical ventilation is provided [5].

Currently, six antivenoms are claimed to be effective against envenomings from N. melanoleuca [6]. Due to the severity of envenomings, $N$. melanoleuca is classified by the WHO as a category 1 snake of highest medical importance (http://apps.who.int/bloodproducts/snakeantivenoms/database/). Therefore, it is of high relevance to obtain a deep understanding of the composition of $N$. melanoleuca venom. To this date, no quantitative venom proteome has been reported for $N$. melanoleuca, however, several biochemical studies have reported that the venom contains long and short neurotoxins [7,8], cytotoxins [9-11], phospholipases $\mathrm{A}_{2}$ $[12,13]$, and 'weak' toxins $[9,14]$. 
In order to develop safe and effective antivenoms that can protect against envenoming from $N$. melanoleuca, it is not only important to know the venom composition. It is also essential to understand which toxins are the medically most relevant to target. For this purpose, the combination of venomics and the Toxicity Score [15] may be employed to unveil which toxins are the main culprits responsible for the clinical manifestations of N. melanoleuca envenomings. Being able to identify these key toxins may not only help guide traditional antivenom development, but may also aid rational antitoxin discovery approaches based on biotechnology [16].

Here, we report the first toxicovenomics study of the venom of $N$. melanoleuca, providing a quantitative estimation of its proteome alongside an assessment of the medical importance of the individual venom fractions and an evaluation of the immunorecognition pattern of three antivenoms in use in subSaharan Africa.

\section{Materials and Methods}

\subsection{Snake venom}

Venom of N. melanoleuca was obtained from Latoxan SAS, Valence, France, from a pool of 7 specimens collected in Uganda. Venoms from N. nigricollis and $N$. mossambica used for comparison in in vitro enzymatic assays were also obtained from Latoxan from pools of several specimens collected in Tanzania. Venom from Bothrops asper was obtained as a pool from several specimens from Costa Rica kept at Instituto Clodomiro Picado, Universidad de Costa Rica, Costa Rica.

\subsection{Venom separation by reverse-phase HPLC and SDS-PAGE}

Following the 'snake venomics' analytical strategy, crude venom was 
fractionated involving a combination of RP-HPLC and SDS-PAGE separation [17]. Two mg of venom was dissolved in $200 \mu \mathrm{L}$ of water containing $0.1 \%$ trifluoroacetic acid (TFA; solution A) and separated by RP-HPLC (Agilent 1200) on a $\mathrm{C}_{18}$ column ( $250 \times 4.6 \mathrm{~mm}, 5 \mu \mathrm{m}$ particle; Supelco). Elution was carried out at $1 \mathrm{~mL} / \mathrm{min}$ by applying a gradient towards solution B (acetonitrile, containing $0.1 \%$ TFA): $0 \%$ B for $5 \min , 0-15 \%$ B over $10 \min , 15-45 \%$ B over $60 \min , 45-70 \%$ B over 10 min, and $70 \% \mathrm{~B}$ over $9 \mathrm{~min}$, as previously described [18]. Fractions were collected manually, dried in a vacuum centrifuge, redissolved in water, reduced with $5 \% \quad \beta$ mercaptoethanol at $100^{\circ} \mathrm{C}$ for $5 \mathrm{~min}$, and further separated by SDS-PAGE in $15 \%$ gels. Colloidal Coomassie blue G-250 was used for proteins staining, and a ChemiDoc $^{\circledR}$ recorder and ImageLab ${ }^{\circledR}$ software (Bio-Rad) were used to acquire gel images.

\subsection{Protein identification by tandem mass spectrometry of tryptic peptides}

From the polyacrylamide gels protein bands were excised and subjected to reduction (10 $\mathrm{mM}$ dithiothreitol), alkylation (50 $\mathrm{mM}$ iodoacetamide), and overnight in-gel digestion with sequencing grade trypsin (Sigma), in $50 \mathrm{mM}$ ammonium bicarbonate at $37{ }^{\circ} \mathrm{C}$. Tryptic peptides were extracted with $50 \%$ acetonitrile containing $1 \%$ TFA, and analyzed by MALDI-TOF-TOF on an AB4800-Plus Proteomics Analyzer (Applied Biosystems). Digested and extracted peptides were mixed with an equal volume of saturated $\alpha$-cyano-hydroxycinnamic acid (in $50 \%$ acetonitrile, $0.1 \%$ TFA), and spotted $(1 \mu \mathrm{L})$ onto an Opti-TOF 384-well plate, dried, and analyzed in positive reflector mode. TOF spectra were acquired using 500 shots at a laser intensity of 3000 . TOF/TOF fragmentation spectra were acquired using 500 shots at a laser intensity of 3900 for the automatically selected ten most intense 
precursor ions. CalMix ${ }^{\circledR}$ standards (ABSciex) spotted onto the same plate were used for external calibration in each run. Resulting spectra were searched against the UniProt/SwissProt database for Serpentes (20150217) using ProteinPilot ${ }^{\circledR}$ v.4 and the Paragon $^{\circledR}$ algorithm (ABSciex) at $\geq 95 \%$ confidence, or, in few cases, manually interpreted, and the deduced sequences searched using BLAST (http://blast.ncbi.nlm.nih.gov) for assignment of protein family by similarity.

\subsection{Relative protein abundance estimations}

The relative abundance of the venom proteins was estimated using the ChemStation $^{\circledR}$ software (Agilent) to integrate the areas of their chromatographic peaks at a wavelength of $215 \mathrm{~nm}$, roughly corresponding to peptide bond abundance [17]. When HPLC peaks contained several electrophoretic bands, ImageLab ${ }^{\circledR}$ (BioRad) was used to assign their percentage distributions by densitometry. Finally, for electrophoretic bands containing more than one protein according to MALDI-TOFTOF analysis, their percentage distributions were estimated based on the corresponding intensities of the intact protein ions, as observed in the nESI-MS analysis. For this, a $10 \mu \mathrm{L}$ sample of the HPLC fraction was loaded into a metalcoated capillary (Proxeon) and directly infused into a nano-spray source of a QTrap 3200 mass spectrometer (Applied Biosystems) operated at $1300 \mathrm{~V}$ in enhanced multicharge mode. Deconvolution of spectra was performed with the aid of the Bayesian protein reconstruction tool of Analyst v.1.5. Intensities lower than 5\% (relative to the major protein ions in these mixtures) were considered as traces. Protein abundances were calculated on the basis of protein content percentage (w\%).

\subsection{In vitro enzymatic activities}




\subsubsection{Phospholipase $A_{2}$ activity}

$\mathrm{PLA}_{2}$ activity was assayed using the monodisperse synthetic chromogenic substrate 4-nitro-3-octanoyloxybenzoic acid (NOBA) [19]. $25 \mu \mathrm{L}$ of solution, containing various amounts of venom, were mixed with $200 \mu \mathrm{L}$ of $10 \mathrm{mM}$ Tris, 10 $\mathrm{mM} \mathrm{CaCl} 2,0.1 \mathrm{M} \mathrm{NaCl}, \mathrm{pH} 8.0$, and $25 \mu \mathrm{L}$ of NOBA to achieve a substrate concentration of $0.32 \mathrm{mM}$. Plates were incubated at $37{ }^{\circ} \mathrm{C}$ for $60 \mathrm{~min}$, and absorbances were recorded at $405 \mathrm{~nm}$ (Multiskan FC, Thermo Scientific). For comparative purposes, the activities of the venoms of $N$. mossambica, N. nigricollis, and the viperid snake Bothrops asper were also assessed.

\subsubsection{Proteinase activity}

Proteinase activity was assayed by adding $20 \mu \mathrm{g}$ of venom to $100 \mu \mathrm{L}$ of azocasein $\left(10 \mathrm{mg} / \mathrm{mL}\right.$ in $50 \mathrm{mM}$ Tris- $\mathrm{HCl}, 0.15 \mathrm{M} \mathrm{NaCl}, 5 \mathrm{mM} \mathrm{CaCl}_{2}$ buffer, $\mathrm{pH}$ 8.0), and the mixture was incubated for $90 \mathrm{~min}$ at $37^{\circ} \mathrm{C}$. The reaction was terminated by addition of $200 \mu \mathrm{L}$ of $5 \%$ trichloroacetic acid. After centrifugation ( $5 \mathrm{~min}, 6,000 \times$ g), $150 \mu \mathrm{L}$ of supernatants were mixed with $100 \mu \mathrm{L}$ of $0.5 \mathrm{M} \mathrm{NaOH}$, and absorbances were recorded at $450 \mathrm{~nm}$ (Multiskan FC, Thermo Scientific). The absorbance of azocasein incubated with distilled water alone was used as a blank, being subtracted from all readings [20]. For comparative purposes, the activities of the venoms of $N$. mossambica, N. nigricollis, and Bothrops asper were also assessed.

\subsection{Toxicological profiling}

\subsubsection{Animals}

In vivo assays were performed in CD-1 mice of both sexes, provided by Instituto Clodomiro Picado, following protocols approved by the Institutional 
Committee for the Use and Care of Animals (CICUA), University of Costa Rica. Mice were provided food and water ad libitum.

\subsubsection{Toxicity of crude venom and isolated venom fractions}

The acute toxicity of venom fractions was initially screened by intravenous (i.v.) injection of $10 \mu \mathrm{g}$ of toxin per mouse $(0.53 \mathrm{mg} / \mathrm{kg})$ for all fractions devoid of snake venom metalloproteinases (SVMPs) in groups of three mice (18-20 g body weight). Fractions that were not lethal at this level were not further investigated, whereas precise $\mathrm{LD}_{50} \mathrm{~S}$ were determined in groups of four mice for fractions which did kill mice at this dose, and for the whole venom. Toxicity Scores were calculated according to Laustsen et al. [15], on the basis of the abundance (w\%) of each fraction. Additionally, a Molecular Toxicity Score was introduced, which was calculated using the molecular abundance (mol\%) of each fraction based on the molecular mass of identified toxins. Various amounts of venom or venom fractions were dissolved in phosphate-buffered saline (PBS; $0.12 \mathrm{M} \mathrm{NaCl}, 0.04 \mathrm{M}$ sodium phosphate buffer, $\mathrm{pH}$ 7.2) and injected in the caudal vein, in a volume of $100 \mu \mathrm{L}$. Deaths occurring within $24 \mathrm{~h}$ were recorded, and $\mathrm{LD}_{50} \mathrm{~S}$ were calculated by probits [21], using the BioStat ${ }^{\circledR}$ software (AnalySoft).

\subsection{Antivenoms}

Polyspecific antivenoms from the following manufacturers were employed: (a) SAIMR (South African Institute for Medical Research) Polyvalent Snake Antivenom from South African Vaccine Producers (Pty) Ltd (batch number BC02645, expiry date 07/2016); (b) Snake Venom Antivenom (Central Africa) from VINS Bioproducts 
Ltd (batch 12AS13002, expiry date 04/2017); (c) Snake Venom Antivenom (African) from VINS Bioproducts Ltd (batch 13022, expiry date 01/2018).

2.8 Immunoreactivity of antivenoms against crude venom and venom fractions by ELISA

Wells in MaxiSorp ${ }^{\mathrm{TM}}$ plates (NUNC, Roskilde, Denmark) were coated with 1 $\mu \mathrm{g}$ of each HPLC venom fraction, or crude venom, dissolved in $100 \mu \mathrm{L}$ PBS overnight. Next day, the wells were washed three times with PBS and blocked by adding $100 \mu \mathrm{L}$ PBS containing 2\% (w:v) bovine serum albumin (BSA, Sigma), and incubated at room temperature for $1 \mathrm{~h}$. Then, plates were washed five times with PBS. A dilution of each antivenom in PBS $+2 \%$ BSA was prepared, and $100 \mu \mathrm{L}$ of these solutions were added to each well in triplicates and incubated for $2 \mathrm{~h}$. Plates were then washed five times with PBS. Subsequently, $100 \mu \mathrm{L}$ of a 1:2000 dilution of conjugated antibody (Sigma A6063, rabbit anti-horse IgG (whole molecule)-alkaline phosphatase in PBS $+1 \%$ BSA) was then added to each well. Following $2 \mathrm{~h}$ of incubation, the wells were washed five times with FALC buffer $(0.05 \mathrm{M}$ Tris, $0.15 \mathrm{M} \mathrm{NaCl}, 20 \mu \mathrm{M}$ $\mathrm{ZnCl}_{2}, 1 \mathrm{mM} \mathrm{MgCl} 2, \mathrm{pH} 7.4$ ). Color development was achieved by addition of 100 $\mu \mathrm{L} p$-nitrophenyl phosphate $(1 \mathrm{mg} / \mathrm{mL}$ in $9.7 \% \mathrm{v} / \mathrm{v}$ diethanolamine buffer, $\mathrm{pH} 9.8)$ and absorbances at $405 \mathrm{~nm}$ were recorded (Multiskan FC, Thermo Scientific).

\subsection{Results and Discussion}

\subsection{Venomics}

A bottom-up venomic characterization of $N$. melanoleuca venom was performed. Using RP-HPLC, the venom was resolved into 33 fractions, where the first, second and sixth fractions eluting from the column did not contain proteins as found in SDS- 
PAGE. Further resolving by SDS-PAGE of the 30 remaining fractions yielded 63 bands (Figure 2), of which the protein identities for 62 bands were positively identified upon in-gel digestion and MALDI-TOF-TOF analysis. Within these bands a total of 52 different proteins were identified. As described previously [22,23], some fractions contained toxins in both monomer and dimer form, as exemplified by fraction number 10 (see Figure 2). To uncover the overall protein composition of $N$. melanoleuca venom, the identified proteins were assigned to families and expressed as percentages of total protein content (see Figure 3 and Table 1). The most abundant proteins were found to belong to the three-finger toxin (3FTx) family $(57.1 \mathrm{w} \%)$, followed by proteins from the phospholipase $\mathrm{A}_{2}\left(\mathrm{PLA}_{2}\right)$ family $(12.9 \mathrm{w} \%)$ (Figure 3). 3FTxs in elapid venoms share a common structural scaffold consisting of 60-80 amino acids, with three $\beta$-stranded loops extending from a small, globular, hydrophobic core [24-26]. Despite this highly conserved structure, 3FTxs display a wide range of activities [27], although the main 3FTxs identified in the venom of $N$. melanoleuca are type I and II $\alpha$-neurotoxins and cytotoxins (see Table 1). Both type I and II $\alpha$-neurotoxins target the nicotinic acetylcholine receptor at the end-plate of muscle fibers, causing flaccid paralysis in victims and prey, potentially culminating in respiratory failure and death [28-30]. The cytotoxins identified in this study derive from the type IA cytotoxin sub-subfamily. Cobra cytotoxins are amphiphilic toxins known for inducing cellular damage through disruption of the cell membrane, which may lead to tissue necrosis $[31,32]$. However, experimental and clinical envenomings by $N$. melanoleuca are not characterized by tissue necrosis possibly due to the relatively low content of cytotoxins as compared to the predominant $\alpha$-neurotoxins.

The second-most abundant toxin family found in the venom of $N$. melanoleuca is the phospholipase $\mathrm{A}_{2}\left(\mathrm{PLA}_{2}\right)$ family $(12.9 \mathrm{w} \%)$, which is generally found in 
abundance in both viperids and elapids and, in the case of elapids, has evolved from pancreatic $\mathrm{PLA}_{2}$ digestive enzymes [33]. The catalytic function of $\mathrm{PLA}_{2} \mathrm{~S}$ is to cleave phospholipids at the $s n-2$ position in the glycerol backbone. In snake venoms, however, $\mathrm{PLA}_{2} \mathrm{~S}$ not only play a role in the digestion of prey, but also exhibit a variety of toxicological effects [34]. As in other elapid venoms, the $\mathrm{PLA}_{2} \mathrm{~S}$ found in $N$. melanoleuca belong to the Group I, catalytically-active D49 enzymes [33]. In agreement, $N$. melanoleuca venom showed $\mathrm{PLA}_{2}$ activity, similar to the venom of $N$. nigricollis but lower than that of venoms of N. mossambica and Bothrops asper (Figure 4A). Despite the presence of 9.7\% SVMPs in the venom proteome, very low proteinase activity was observed on azocasein (Figure 4B). It is likely that the SVMPs of $N$. melanoleuca have restricted substrate specificity as observed in other elapid species $[22,23]$

Other protein families found in lower proportions in the venom of $N$. melanoleuca include cysteine-rich secretory proteins (CRISP; 7.6 w\%), Kunitz-type serine proteinase inhibitors (BPTI/Kunitz; $3.8 \mathrm{w} \%$ ), flavin monoamine oxidases (FMO; $2.5 \mathrm{w} \%$ ), and traces of nerve growth factors (NGF $<0.4 \mathrm{w} \%$ ), ohanin/vespryn family (OHA; $<0.5$ w\%), DNA/RNA endonucleases (DRE $<0.3$ w\%), endonuclease/phosphodiesterase (PDE; $1.1 \mathrm{w} \%$ ), glutathione peroxidase family (GPF; $0.9 \mathrm{w} \%$ ), type-B carboxylesterase/lipase family (CELF; $1.1 \mathrm{w} \%$ ), and selectins (SUSHI; $<0.3$ w\%).

\subsection{Toxicity of venom fractions}

Toxicity testing was carried out for all venom fractions devoid of SVMPs, since the solvents used for RP-HPLC denature these proteinases (Table 2). First, the $\mathrm{LD}_{50}$ of crude venom was determined to be $0.66 \mathrm{mg} / \mathrm{kg}$ ( $95 \%$ confidence interval $0.49-0.92$ 
$\mathrm{mg} / \mathrm{kg}$ ). This value was higher than previously determined $\mathrm{LD}_{50}$ S (i.v. $0.289 \mathrm{mg} / \mathrm{kg}$ ), reported on http://snakedatabase.org/pages/LD50.php. It is likely that this can be explained by geographical variation in venom toxicity which is known to occur in species having a wide distribution [35]. A cut-off value of $10 \mu \mathrm{g}$ per mouse $(0.53$ $\mathrm{mg} / \mathrm{kg}$ ) was chosen for toxicity screening of the venom fractions. From Table 2 it was evident that the majority of fractions inducing lethality within $24 \mathrm{~h}$ were those containing type I and II $\alpha$-neurotoxins. $\mathrm{LD}_{50} \mathrm{~S}$ were determined for fractions that showed lethality at $0.53 \mathrm{mg} / \mathrm{kg}$, more specifically fractions $3,4,5$, and 8 , as depicted in Table 2. These $\mathrm{LD}_{50} \mathrm{~S}$ were lower than the overall $\mathrm{LD}_{50}$ of the crude venom suggesting that the toxins present in these fractions are of high medical relevance. According to their Toxicity Scores, the most potent fraction was fraction 8 (TS $=88$, Molecular TS $=115.5$ ), containing a homolog of Long neurotoxin OH-55 Ophiophagus hannah (Q53B58), Long neurotoxin 2 Naja melanoleuca (P01338), and Weak toxin S4C11 Naja melanoleuca (P01400). Previous studies have found Weak toxin S4C11 Naja melanoleuca (P01400) to have an $\mathrm{LD}_{50}$ of $20 \mathrm{mg} / \mathrm{kg}$ [9], strongly suggesting that the long neurotoxins are the cause of the high toxicity of this fraction. From the MALDI-TOF-TOF analysis fractions 3, 4, and 5 were found to contain similar $\alpha$-neurotoxins, with all three fractions having $\mathrm{LD}_{50} \mathrm{~S}$ in the same range. Due to differences in abundances, Toxicity Scores for these fractions differed (TS $=59.2$, 4.6, and 10.0, Molecular TS $=78.8,15.0$, and 6.9, respectively). Nevertheless, the similarity in both the sequences obtained (Table 1) and the $\mathrm{LD}_{50} \mathrm{~s}$ (Table 2) suggest that the toxins present in these fractions are likely to be similar isoforms. No other toxins were found to show lethality at the pre-determined cut-off value. Mice injected with fractions $3,4,5$, and 8 showed evident manifestations of respiratory paralysis, indicating that the cause of death was neurotoxin-induced respiratory arrest. 
The toxicity analysis of fractions strongly suggests that other venom components, such as $\mathrm{PLA}_{2} \mathrm{~s}$, do not play a central role in the overall toxicity. Despite the fact that neurotoxic PLA 2 s occur in many elapid snake venoms [36], and although neurotoxic PLA $\mathrm{P}_{2} \mathrm{~S}$ have been described in some Naja sp venoms [37], in general the neurotoxicity of cobra venoms is based on the action of post-synaptically acting 3FTxs. Likewise, other minor components present in $N$. melanoleuca venom do not seem to exert lethal effects either, as judged by our toxicity screening.

According to their Toxicity Scores, the most therapeutically relevant targets of N. melanoleuca to be neutralized with antivenom were found to be homologs of Alpha-neurotoxin NTX-1 from N. sputratix (Q9YGJ6), Short neurotoxin 1 from $N$. melanoleuca (P01424), Long neurotoxin 2 from N. melanoleuca (P01388), and Long neurotoxin $\mathrm{OH}-55$ O. hannah (Q53B58) which are $\alpha$-neurotoxins that bind to the nicotinic acetylcholine receptor, thereby abrogating neuromuscular transmission.

\subsection{Immunoprofiling of antivenoms}

Three polyspecific antivenoms, distributed in sub-Saharan Africa, were tested for their ability to recognize $N$. melanoleuca crude venom and fractions by ELISA. First, ELISA titration curves were determined against immobilized crude venom with the highest binding found to be VINS African, followed by SAVP, and VINS Central Africa, when normalized according to protein concentration (Figure 5). The immunization mixture of both VINS African and SAVP contain the venom of $N$. melanoleuca, whereas VINS Central Africa solely consists of venom from three species of the Viperidae family and Dendroaspis polylepis. Thus, cross-reactivity between similar toxins present in these species and $N$. melanoleuca is likely to exist. 
When using solid-phase immunoassays of antivenoms against crude venoms, prediction of cross-reactivity may be of limited value as antibodies tend to bind to the highly immunogenic venom components, which are not always the most medically relevant ones. Therefore, it is important to consider the recognition pattern for antivenoms against individual venom components or fractions. To further investigate these immunorecognition patterns, all three antivenoms were subjected to yet another ELISA assay against the different venom fractions (Figure 6). From these results it was observed that the three antivenoms generally have a similar recognition pattern. However, the SAVP antivenom does appear to have higher antibody titers than the other antivenoms against the medically most relevant fractions containing the $\alpha$ neurotoxins (fractions 3, 4, 5, and 8) (see Figure 6).

\subsection{Concluding remarks and outlook}

In the present study, the venom of $N$. melanoleuca was, for the first time, subjected to a thorough toxicovenomics analysis. This revealed that the venom was dominated by three-finger toxins $\left(57.1 \mathrm{w} \%\right.$ of the venom) and phospholipase $\mathrm{A}_{2} \mathrm{~S}(12.9 \mathrm{w} \%$ of the venom), of which particularly the three-finger toxins were determined to be the most toxic fractions of the venom evaluated by their Toxicity Score. Additionally, other protein families (CRISPs, nerve growth factor, Kunitz-type serine protease inhibitor, ohanin/vespryn, SVMPs, DNA/RNA non-specific endonuclease, endonuclease/phosphodiesterase, flavin monoamine oxidase, glutathione peroxidase, Type-B carboxylesterase/lipase, and selectins) were determined to be present in the venom. Immunoprofiling of three antivenoms by ELISA with the different fractions of $N$. melanoleuca venom revealed a similar pattern of immunorecognition, although the South African antivenom exhibited slightly higher signals against the 
toxicologically relevant neurotoxins. Our toxicovenomic observations indicate that an effective antivenom against the venom of $N$. melanoleuca should contain neutralizing antibodies against venom components having homology to the $\alpha$-neurotoxins Alphaneurotoxin NTX-1 from $N$. sputratix (Q9YGJ6), Short neurotoxin 1 from $N$. melanoleuca (P01424), Long neurotoxin 2 from N. melanoleuca (P01388), and Long neurotoxin OH-55 O. hannah (Q53B58). Hopefully, these studies may help lay the foundation for developing more efficacious antivenoms, based on traditional or novel biotechnological approaches.

\section{Acknowledgments}

The authors thank Julián Fernández, Instituto Clodomiro Picado, for his collaboration. We also thank the Department of Drug Design and Pharmacology, University of Copenhagen, the Department of Biotechnology and Biomedicine, Technical University of Denmark, and Instituto Clodomiro Picado, Universidad de Costa Rica, for supporting the research. Finally, the financial support of the following foundations is greatly acknowledged: Erik Birger Christensens Legat (51237/PST), Dansk Tennis Fond, Augustinus Fonden (15-2263), Knud Højgaards Fond (15-015167), Oticon Fonden (15-1921), Vera \& Carl Johan Michaelsens legat, Frants Allings Legat, and Rudolph Als Fondet, and the Novo Nordisk Foundation (NNF16OC0019248). 


\section{References}

[1] P.J. Mirtschin, N. Dunstan, B. Hough, E. Hamilton, S. Klein, J. Lucas, et al., Venom yields from Australian and some other species of snakes, Ecotoxicology. 15 (2006) 531-538.

[2] R. Shine, W.R. Branch, J.K. Webb, P.S. Harlow, T. Shine, J.S. Keogh, Ecology of cobras from southern Africa, J. Zool. 272 (2007) 183-193.

[3] L. Luiselli, F.M. Angelici, Ecological relationships in two Afrotropical cobra species (Naja melanoleuca and Naja nigricollis), Can. J. Zool. Can. Zool. 78 (2000) 191-198.

[4] M. O'Shea, Venomous Snakes of the World, Princetown University Press, 2005.

[5] World Health Organization, Guidelines for the Prevention and Clinical Management of Snakebite in Africa, Brazzaville, World Health Organization (2010). Available in http://www.afro.who.int/en/clusters-aprogrammes/hss/essential-medicines/edm-publications/2731-guidelines-forthe-prevention-and-clinical-management-of-snakebite-in-africa.html

[6] A.H. Laustsen, M. Engmark, C. Milbo, J. Johannesen, B. Lomonte, J.M. Gutiérrez, et al., From fangs to pharmacology: The future of antivenoms, Curr. Pharm. Des. 22 (2016).

[7] R.A. Shipolini, G.S. Bailey, B.E. Banks, The separation of neurotoxin from the venom of Naja melanoleuca and the primary sequence determination., Eur. J. Biochem. 42 (1974) 203-11.

[8] D.P. Botes, Snake venom toxins. The amino acid sequences of toxins b and d from Naja melanoleuca venom., J. Biol. Chem. 247 (1972) 2866-71.

[9] F.H. Carlsson, Snake venom toxins. The primary structure of protein S4C11. A 
neurotoxin homologue from the venom of forest cobra (Naja melanoleuca)., Biochim. Biophys. Acta. 400 (1975) 310-21.

[10] R.A. Shipolini, M. Kissonerghis, B.E. Banks, The primary structure of a major polypeptide component from the venom of Naja melanoleuca., Eur. J. Biochem. 56 (1975) 449-54.

[11] F.H.H. Carlsson, F.J. Joubert, Snake venom toxins The isolation and purification of three cytotoxin homologues from the venom of the forest cobra (Naja melanoleuca) and the complete amino acid sequence of toxin VII1, Biochim. Biophys. Acta - Protein Struct. 336 (1974) 453-469.

[12] F.J. Joubert, Naja melanoleuca (forest cobra) venom. The amino acid sequence of phospholipase A, fraction DE-III., Biochim. Biophys. Acta. 379 (1975) 32944.

[13] F.J. Joubert, The amino acid sequence of phospholipase A, fractions DE-I and DE-II., Biochim. Biophys. Acta. 379 (1975) 345-59.

[14] F.J. Joubert, N. Taljaard, Snake venoms. The amino acid sequences of two Melanoleuca-type toxins., Hoppe-Seyler's Zeitschrift Für Physiol. Chemie. 361 (1980) 425-36.

[15] A.H. Laustsen, B. Lohse, B. Lomonte, M. Engmark, J.M. Gutiérrez, Selecting key toxins for focused development of elapid snake antivenoms and inhibitors guided by a Toxicity Score., Toxicon. 104 (2015) 43-5.

[16] A.H. Laustsen, J.M. Gutiérrez, B. Lohse, A.R. Rasmussen, J. Fernández, B. Lomonte, Snake venomics of monocled cobra (Naja kaouthia) and investigation of human IgG response against venom toxins, Toxicon. 99 (2015) $23-25$.

[17] J. Calvete, Proteomic tools against the neglected pathology of snake bite 
envenoming, Expert Rev Proteomics. (2011) 739-758.

[18] B. Lomonte, W.C. Tsai, J.M. Ureña-Diaz, L. Sanz, D. Mora-Obando, E.E. Sánchez, et al., Venomics of new world pit vipers: Genus-wide comparisons of venom proteomes across Agkistrodon, J. Proteomics. 96 (2014) 103-116.

[19] M. Holzer, S. Mackessy, An aqueous endpoint assay of snake venom phospholipase $\mathrm{A}_{2}$, Toxicon. (1996) 1149-55.

[20] W. Wang, C. Shih, T. Huang, A novel P-I class metalloproteinase with broad substrate-cleaving activity, agkislysin, from Agkistrodon acutus venom, Biochem Biophys Res Commun. (2004) 224-230.

[21] D. Finney, Statistical Methods in Biological Assay, London: Charles Griffin and Company Limited, 1971.

[22] L.P. Lauridsen, A.H. Laustsen, B. Lomonte, J.M. Gutiérrez, Toxicovenomics and antivenom profiling of the Eastern green mamba snake (Dendroaspis angusticeps), J. Proteomics. 136 (2016) 248-261.

[23] A.H. Laustsen, B. Lomonte, B. Lohse, J. Fernández, J.M. Gutiérrez, Unveiling the nature of black mamba (Dendroaspis polylepis) venom through venomics and antivenom immunoprofiling: Identification of key toxin targets for antivenom development., J. Proteomics. 119 (2015) 126-142.

[24] V. Tsetlin, Snake venom alpha-neurotoxins and other "three-finger" proteins., Eur. J. Biochem. 264 (1999) 281-6.

[25] R.M. Kini, R. Doley, Structure, function and evolution of three-finger toxins: Mini proteins with multiple targets, Toxicon. 56 (2010) 855-867.

[26] T. Endo, N. Tamiya, Current view on the structure-function relationship of postsynaptic neurotoxins from snake venoms., Pharmacol. Ther. 34 (1987) $403-51$. 
[27] K. Sunagar, T.N.W. Jackson, E.A.B. Undheim, S.A. Ali, A. Antunes, B.G. Fry, Three-fingered RAVERs: Rapid Accumulation of Variations in Exposed Residues of snake venom toxins., Toxins (Basel). 5 (2013) 2172-208.

[28] C.-I.A. Wang, T. Reeks, I. Vetter, I. Vergara, O. Kovtun, R.J. Lewis, et al., Isolation and structural and pharmacological characterization of $\alpha$-elapitoxinDpp2d, an amidated three finger toxin from black mamba venom., Biochemistry. 53 (2014) 3758-66.

[29] C.M. Barber, G.K. Isbister, W.C. Hodgson, Alpha neurotoxins. Toxicon. 66 (2013) 47-58.

[30] S. Nirthanan, M.C. Gwee, Three-finger alpha-neurotoxins and the nicotinic acetylcholine receptor, forty years on. J. Pharmacol. Sci. 94 (2004) 1-17.

[31] M. Rivel, D. Solano, M. Herrera, M. Vargas, M. Villalta, Á. Segura, et al., Pathogenesis of dermonecrosis induced by venom of the spitting cobra, Naja nigricollis: An experimental study in mice., Toxicon. 119 (2016) 171-179.

[32] P. V. Dubovskii, Y.N. Utkin, Cobra cytotoxins: Structural organization and antibacterial activity, Acta Naturae. 6 (2014) 11-18.

[33] F.F. Davidson, E.A. Dennis, Evolutionary relationships and implications for the regulation of phospholipase $A_{2}$ from snake venom to human secreted forms, J. Mol. Evol. 31 (1990) 228-238.

[34] R.M. Kini, Excitement ahead: Structure, function and mechanism of snake venom phospholipase $A_{2}$ enzymes, Toxicon. 42 (2003) 827-840.

[35] K.Y. Tan, C.H. Tan, S.Y. Fung, N.H. Tan, Venomics, lethality and neutralization of Naja kaouthia (monocled cobra) venoms from three different geographical regions of Southeast Asia, J. Proteomics. 120 (2015) 105-125.

[36] C. Montecucco, J.M. Gutiérrez, B. Lomonte, Cellular pathology induced by 
snake venom phospholipase $A_{2}$ myotoxins and neurotoxins: common aspects of their mechanisms of action., Cell. Mol. Life Sci. 65 (2008) 2897-912.

[37] R. Shashidharamurthy, K. Kemparaju, A neurotoxic phospholipase $\mathrm{A}_{2}$ variant: Isolation and characterization from eastern regional Indian cobra (Naja naja) venom, Toxicon. 47 (2006) 727-733.

[38] F. Joubert, Taljaard N, Complete primary structure of toxin CM-1C from Hemachatus haemachatus (Ringhals) venom, South African J. Chem. 32 (1979) 73-77. 


\section{Figure legends}

Figure 1: Naja melanoleuca in a raised position displaying its characteristic cobra hood.

Figure 2: Separation of $N$. melanoleuca venom proteins using RP-HPLC (A), followed by SDS-PAGE (B). Two mg of venom were fractionated on a $\mathrm{C}_{18}$ column and eluted with an acetonitrile gradient (dashed line), followed by further separation of protein fractions by SDS-PAGE under reducing conditions. Molecular weight markers (M) are indicated in $\mathrm{kDa}$. Coomassie-stained bands were excised, in-gel digested with trypsin, and subjected to MALDI-TOF/TOF analysis for assignment to protein families, as shown in Table 1.

Figure 3: Composition of the $N$. melanoleuca venom proteome according to protein families, expressed as percentages of total protein content based on $\mathrm{w} \%$. 3FTx: threefinger toxins; PLA 2: phospholipase $\mathrm{A}_{2} \mathrm{~S}$; CRISP: cysteine-rich secretory proteins; NGF: Nerve growth factors; KUN: Kunitz-type serine protease inhibitors; OHA: Ohanins/vespryns; MP: Snake venom metalloproteinases; DRE: DNA/RNA nonspecific endonucelases; PDE: Endonucleases/Phosphodiesterases; FMO: Flavin monoamine oxidases; GPF: glutathione peroxidases; CELF: Type-B carboxylesterases/lipases; SUSHI: Selectins; UNK: Unknown.

Figure 4: (A) Comparison of the phospholipase $A_{2}$ activity of $20 \mu \mathrm{g}$ of the venoms of N. melanoleuca, N. mossambica, N. nigricollis, and Bothrops asper on 4-nitro-3octanoyloxybenzoic acid synthetic substrate. (B) Comparison of the proteolytic 
activity of $20 \mu \mathrm{g}$ of venoms of $N$. melanoleuca, $N$. mossambica, $N$. nigricollis, and Bothrops asper on azocasein substrate. Each bar represents mean \pm SD of triplicates.

Figure 5: ELISA titrations of antivenoms against immobilized crude venoms of $N$. melanoleuca. SAVP: SAIMR Polyvalent Snake Antivenom from South African Vaccine Producers. African: Snake Venom Antiserum (African) from VINS Bioproducts Ltd. Central Africa: Snake Venom Antiserum (Central Africa) from VINS Bioproducts Ltd. Control: Normal horse serum. Each point represents mean \pm SD of triplicate wells. Antivenom titrations are represented as volumetric dilutions in (A), or as protein concentrations in (B).

Figure 6: ELISA-based immunoprofiling of antivenoms against HPLC fractions of $N$. melanoleuca venom. For identification of venom fractions see Table 2. SAVP: SAIMR Polyvalent Snake Antivenom from South African Vaccine Producers. African: Snake Venom Antiserum (African) from VINS Bioproducts Ltd. Central Africa: Snake Venom Antiserum (Central Africa) from VINS Bioproducts Ltd. Control: Normal horse serum. Each bar represents mean \pm SD of triplicate wells. 


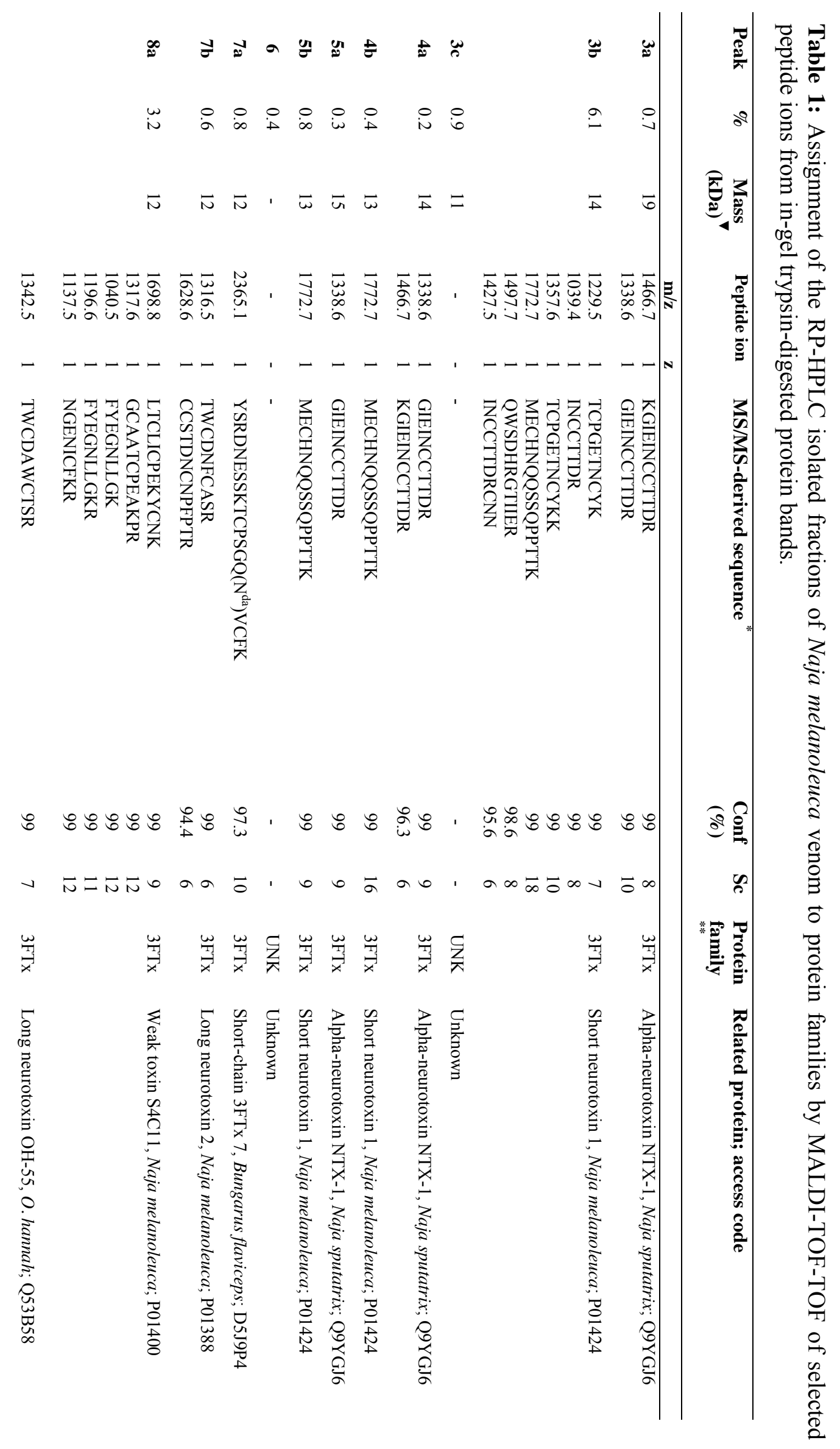




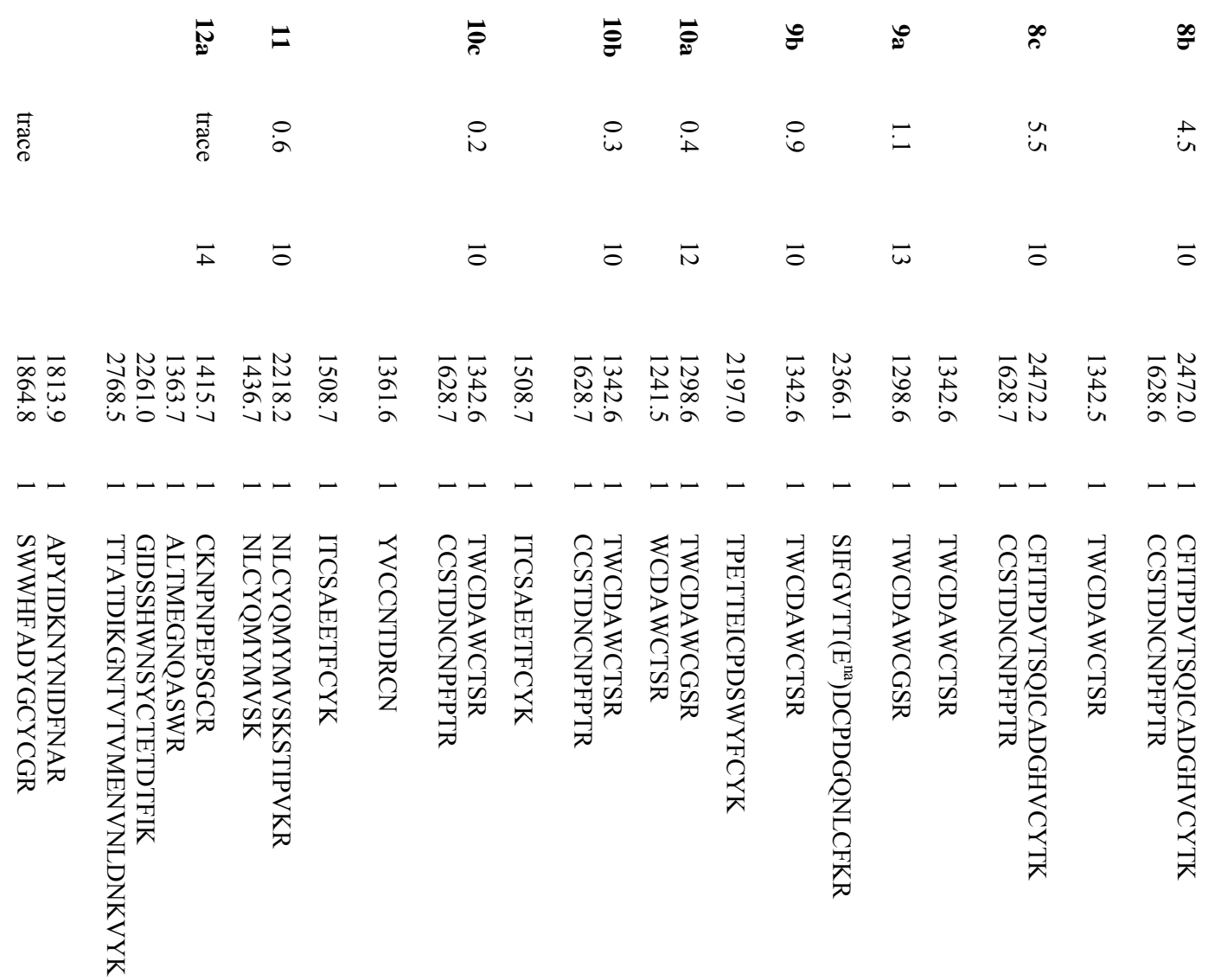

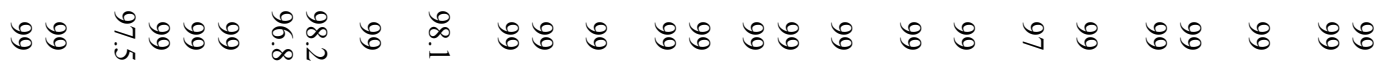

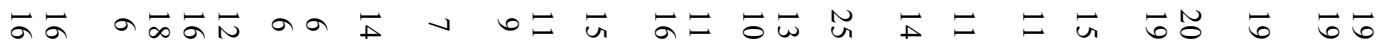

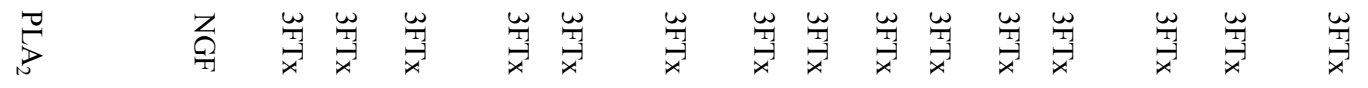

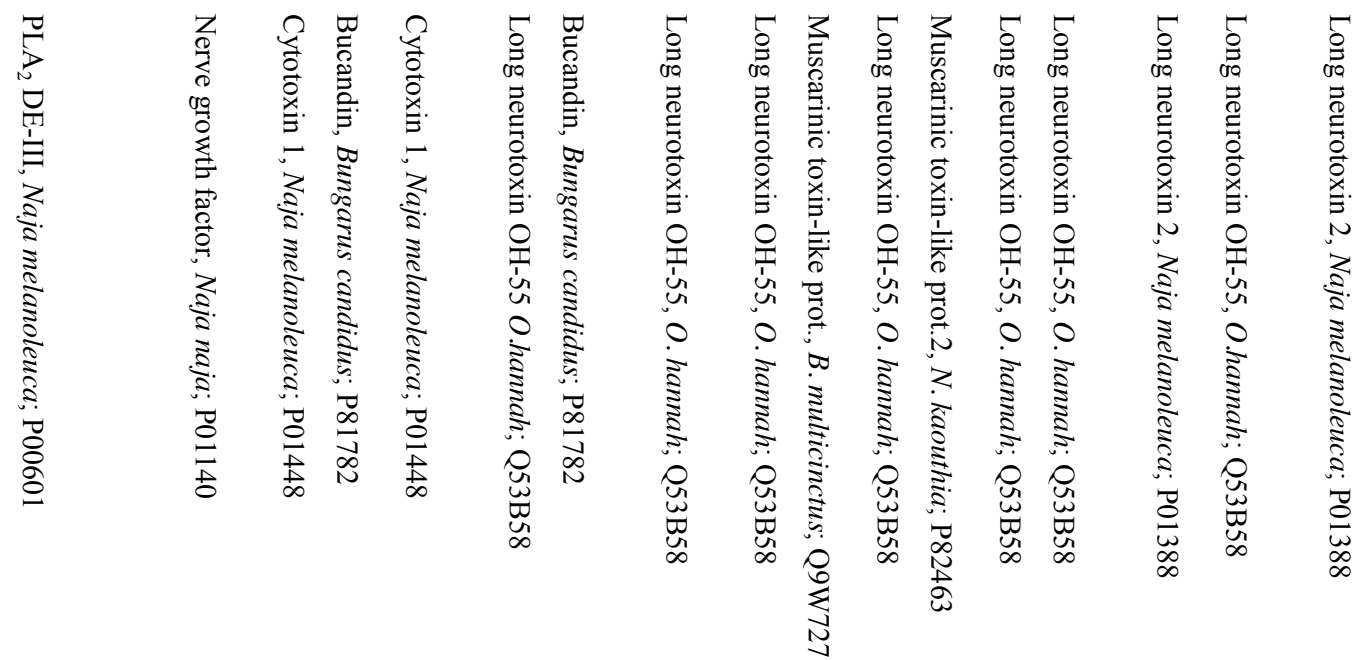




\begin{tabular}{|c|c|c|c|c|c|}
\hline$\overline{v i n}$ & $\overline{\mathrm{y}}$ & $E$ & $\stackrel{F}{ \pm}$ & $\overline{\underline{\omega}}$ & $\bar{\Psi}$ \\
\hline & 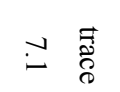 & $\stackrel{\infty}{-}$ & $\stackrel{N}{\sim}$ & $\tilde{O}$ & 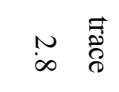 \\
\hline & $\bar{A}$ & $\overrightarrow{0}$ & $\bar{\omega}$ & $\overrightarrow{0}$ & $\bar{\omega}$ \\
\hline
\end{tabular}

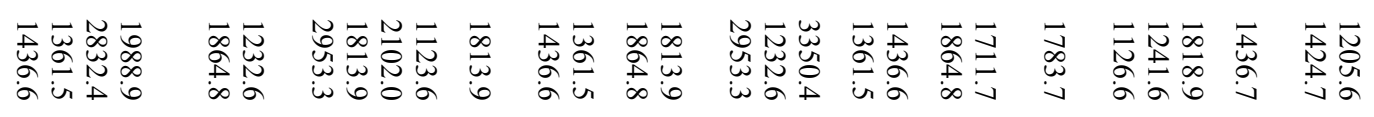

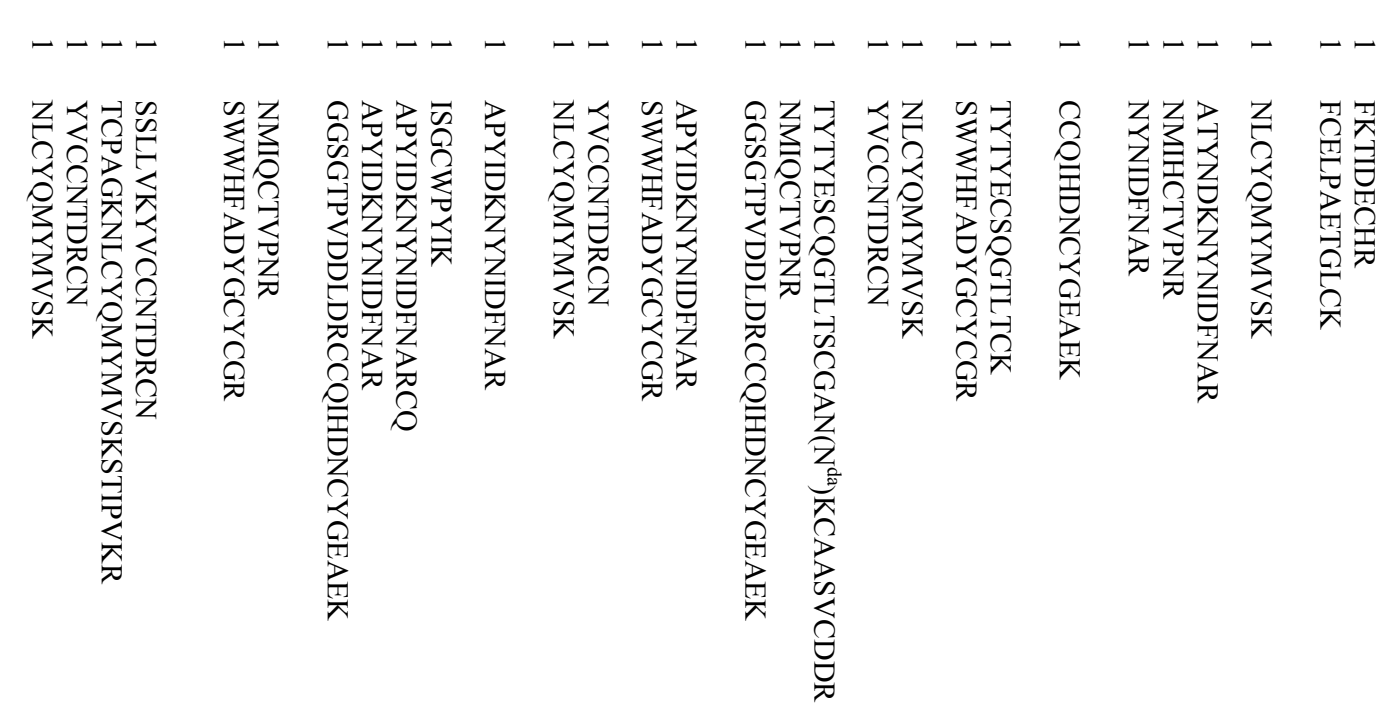

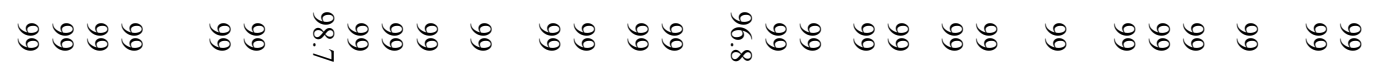
$\vec{\infty}=レ \infty$ 荅

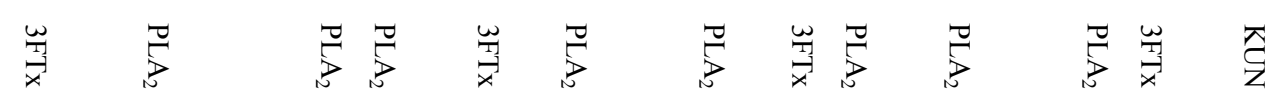

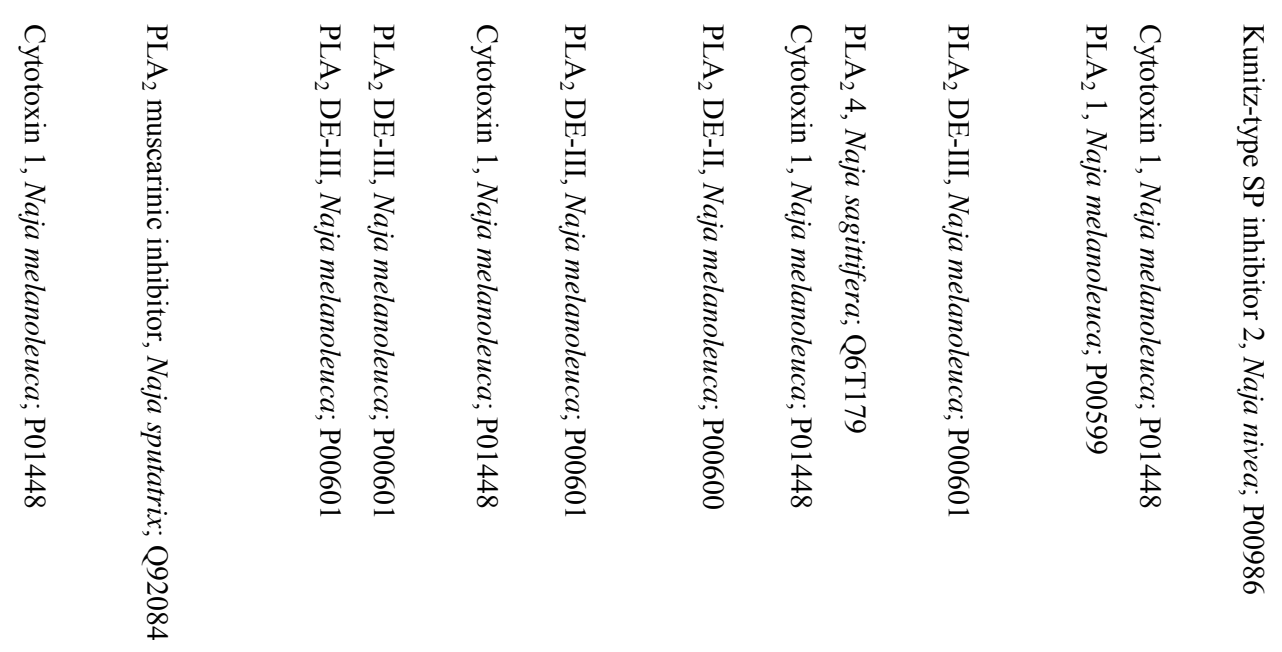




\begin{tabular}{|c|c|c|c|c|c|c|c|}
\hline$\tilde{\mho}$ & $\tilde{W}$ & ర్ & $\Xi$ & 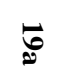 & $\vec{\infty}$ & F & $\bar{g}$ \\
\hline$\dot{0}$ & in & $\stackrel{\vec{B}}{\circ}$ & is & $\stackrel{\circ}{i}$ & i & $\stackrel{\omega}{+}$ & $\bar{\omega}$ \\
\hline - & 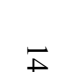 & $=$ & $\mp$ & $\tilde{\perp}$ & o & $=$ & $\overrightarrow{0}$ \\
\hline
\end{tabular}

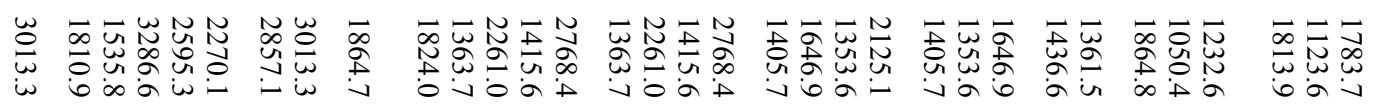

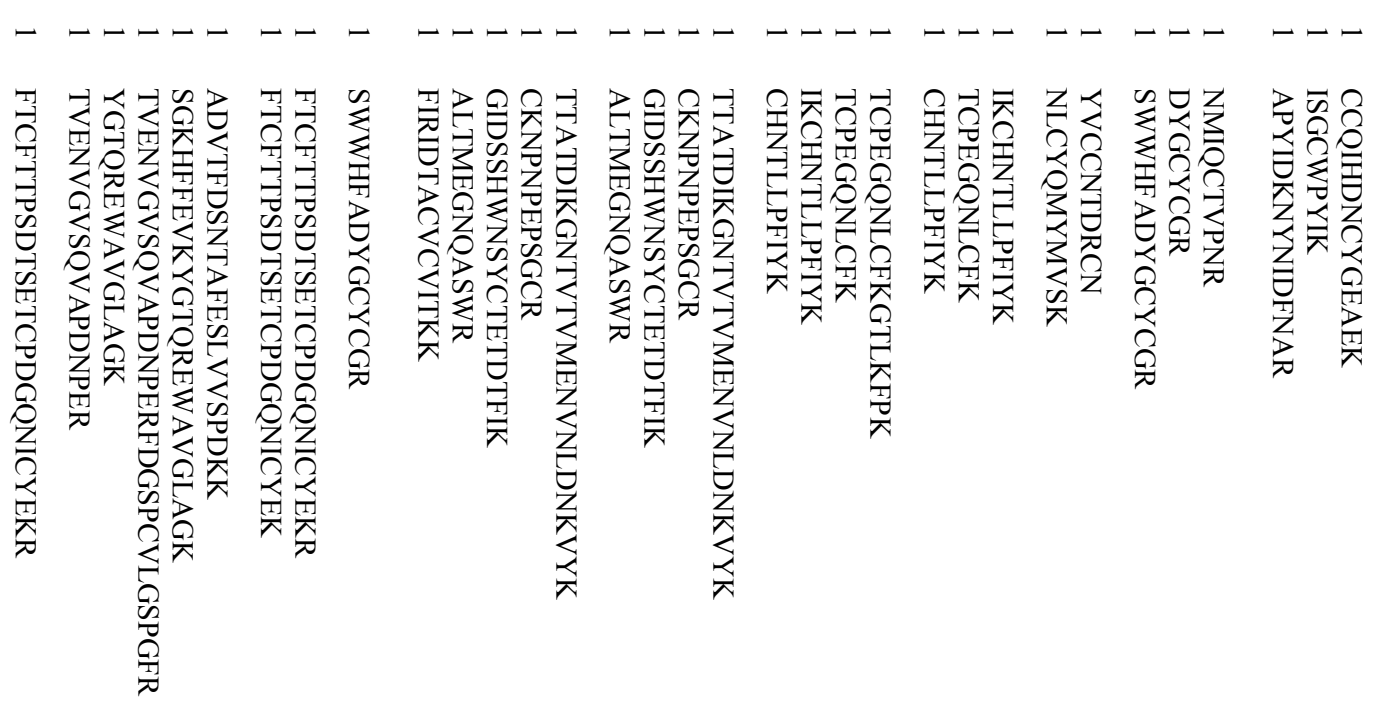

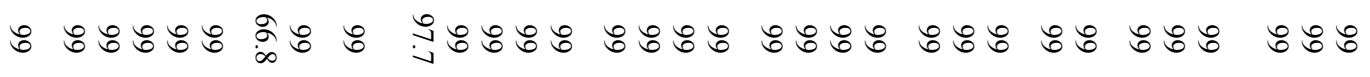

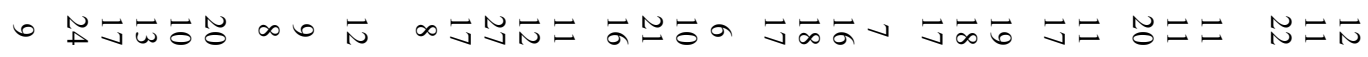

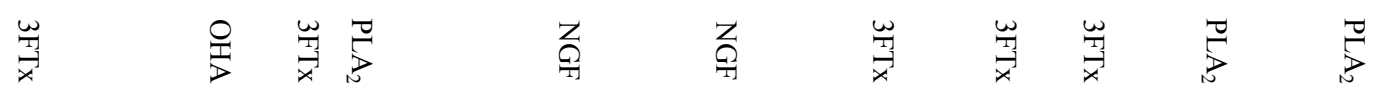

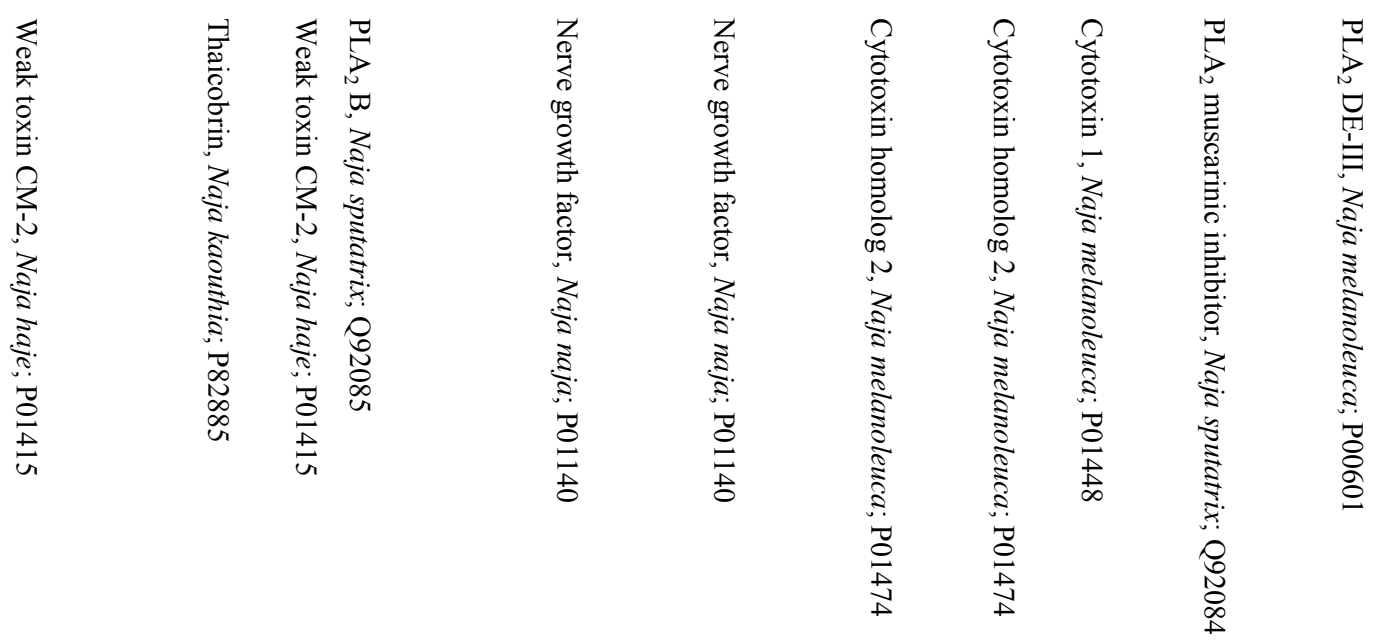




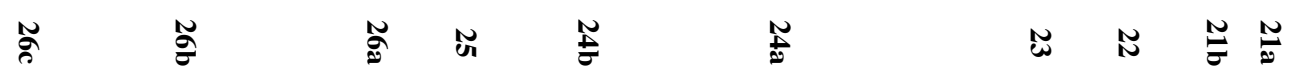

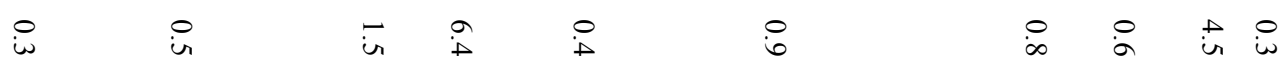

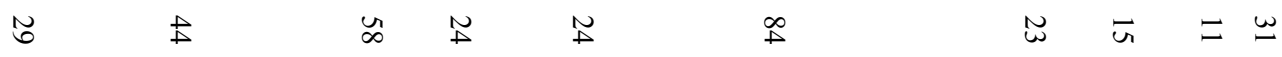

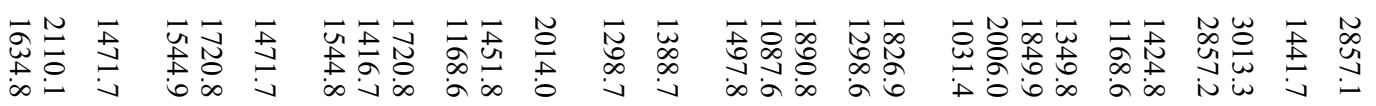

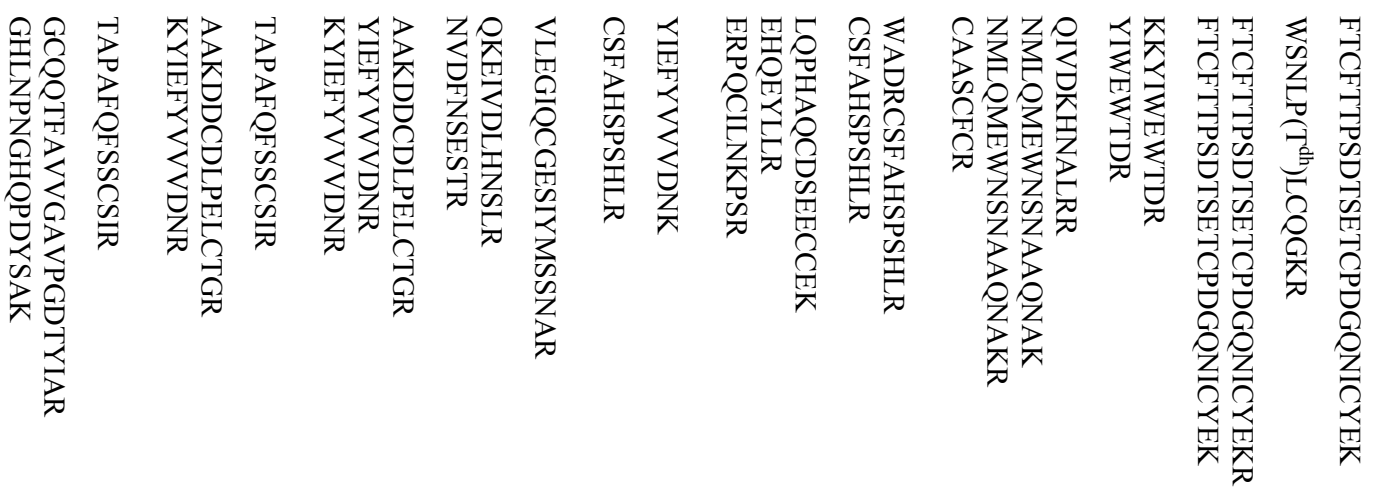

๑ : +

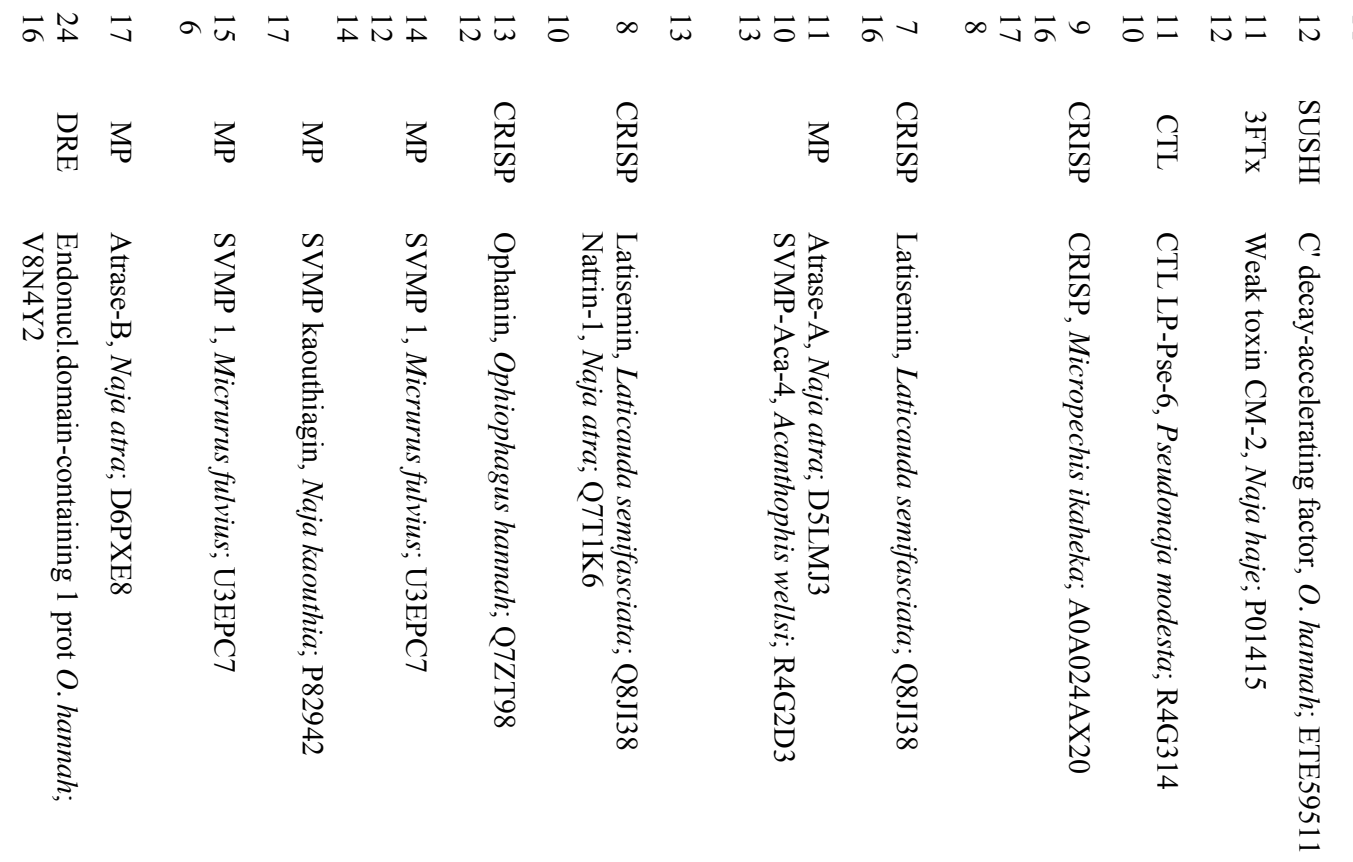




\begin{tabular}{|c|c|c|c|c|c|c|c|}
\hline$\stackrel{\mathscr{W}}{*}$ & :ّ & $\widetilde{\widetilde{\sigma}}$ & 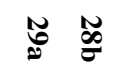 & 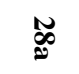 & 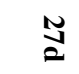 & & บั \\
\hline in & $\stackrel{i}{i}$ & in & is i & $=$ & is & & i \\
\hline 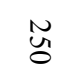 & $\tilde{u}$ & $\ddot{o}$ & $\beth \vec{\omega}$ & $\vec{\infty}$ & \pm & & b \\
\hline
\end{tabular}

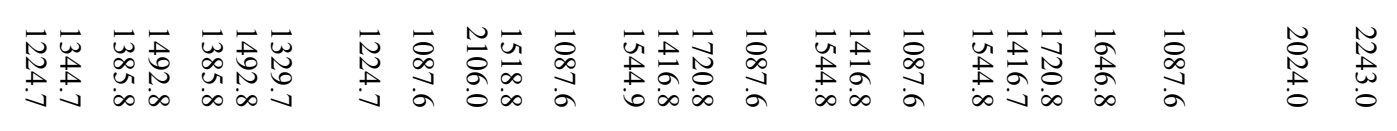

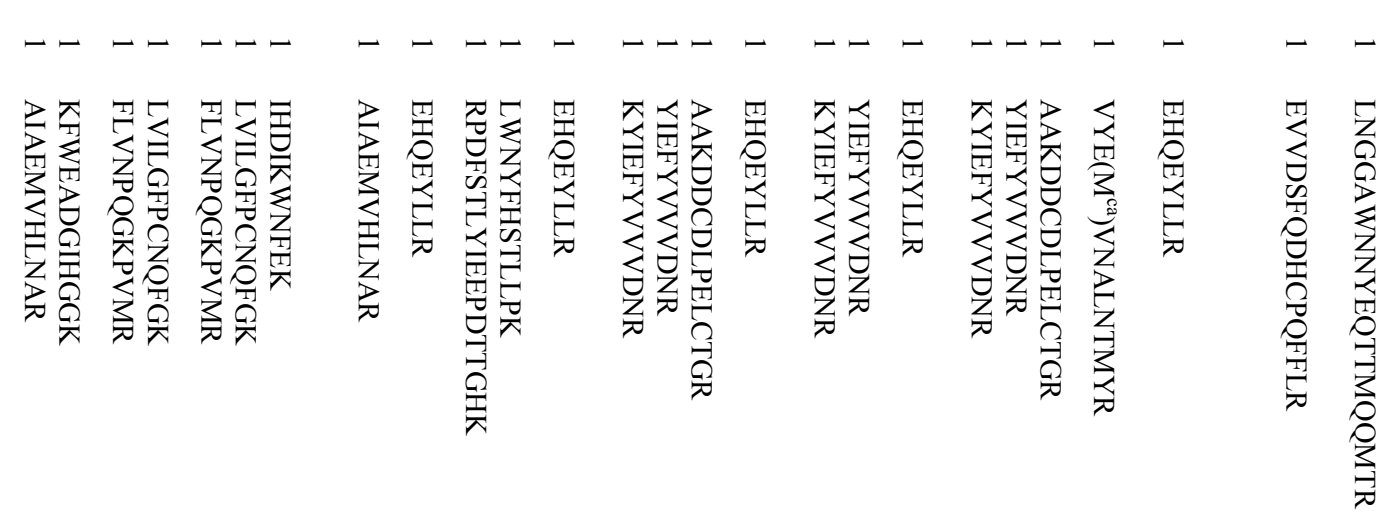

๑ : ৪৪

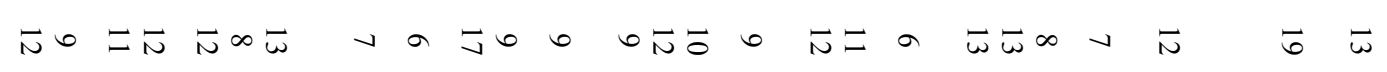

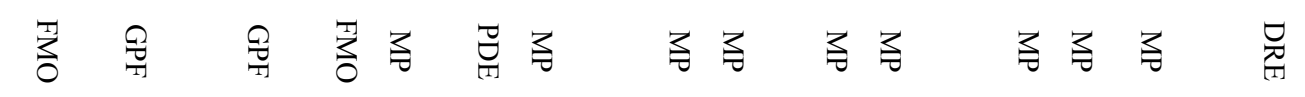

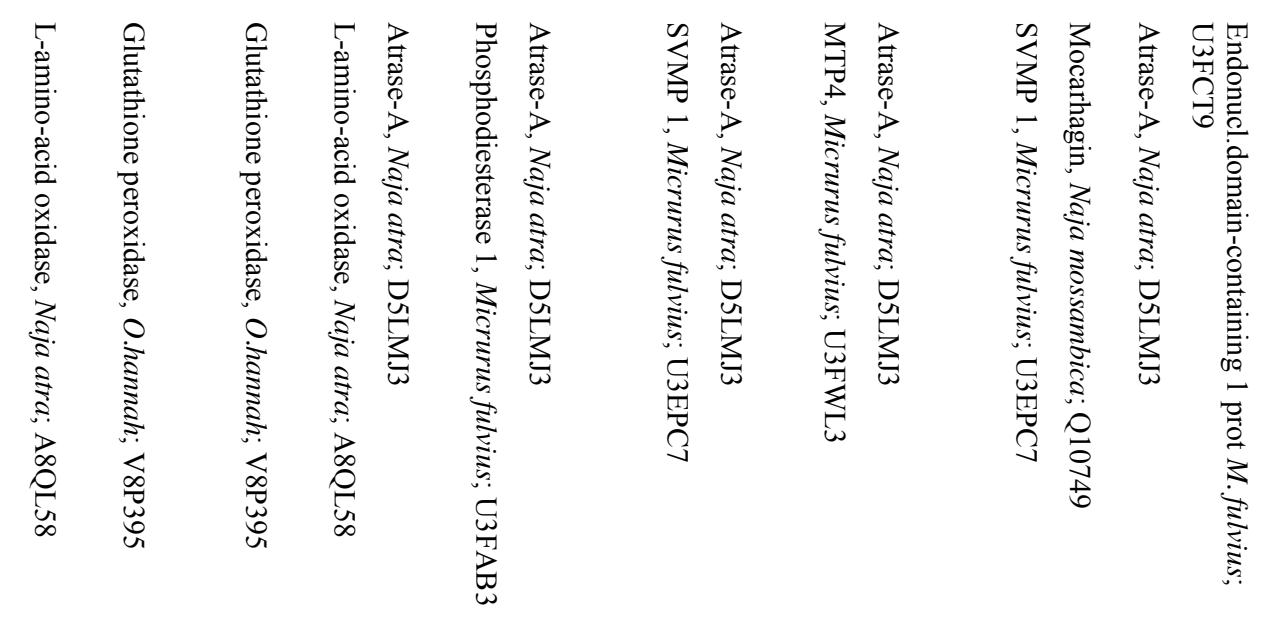




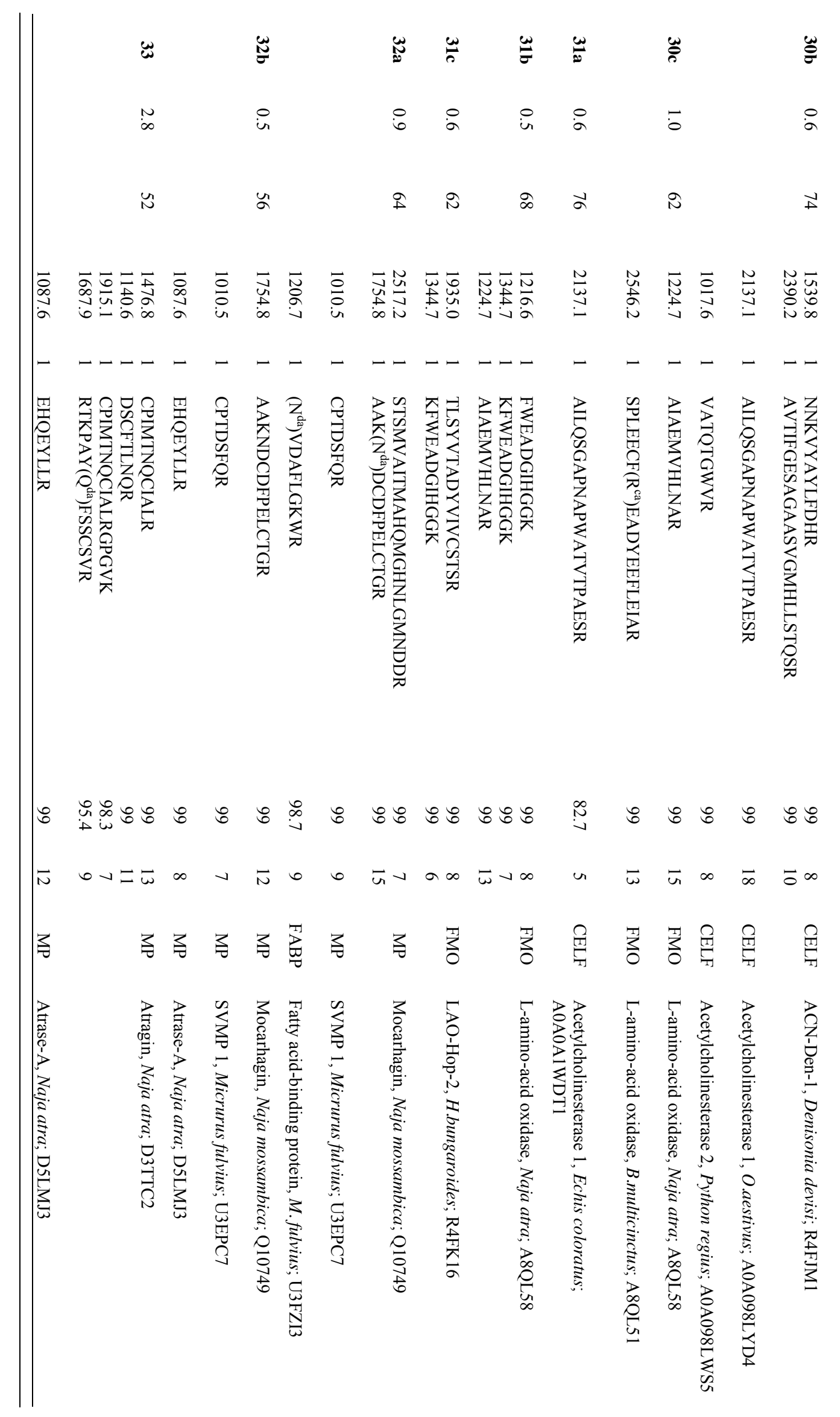




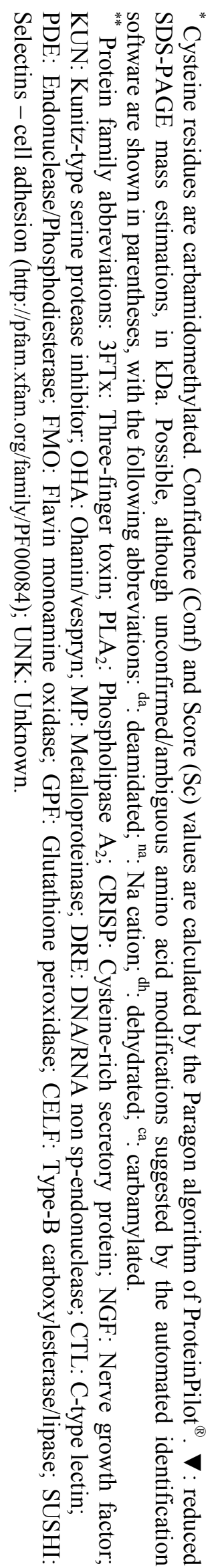




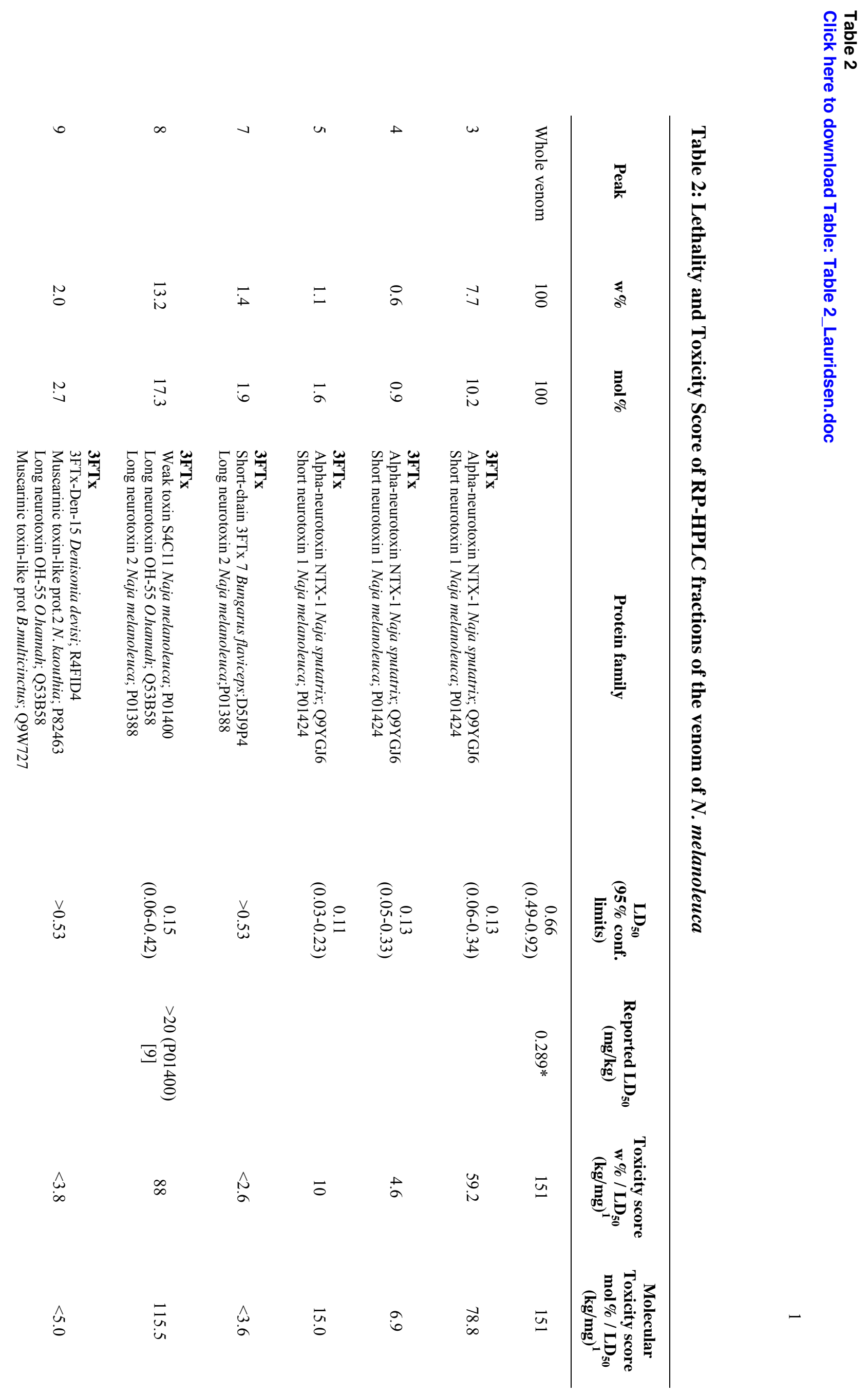




$\begin{array}{llllll}\sigma & \bar{\omega} & \bar{\omega} & \bar{N} & =\end{array}$

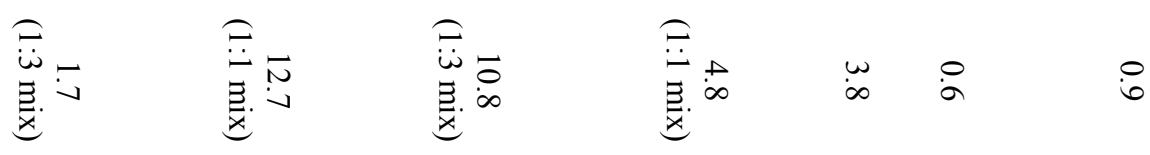

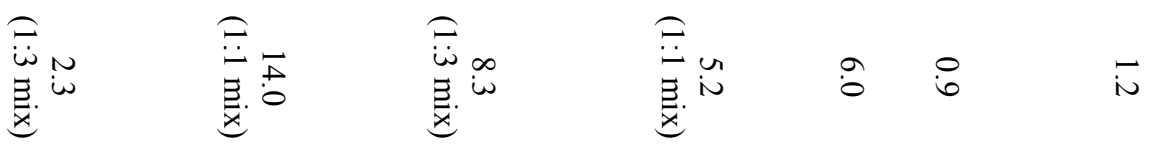

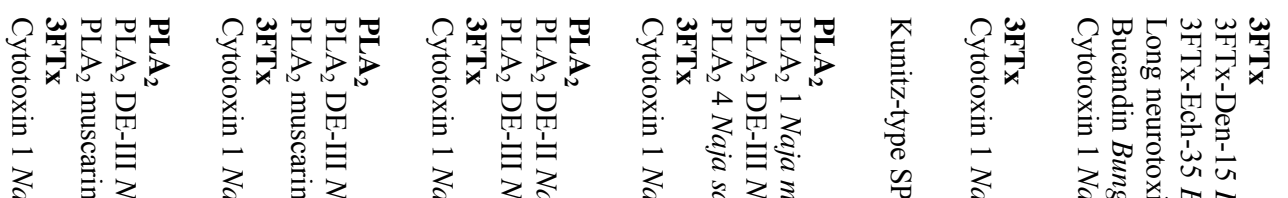

z

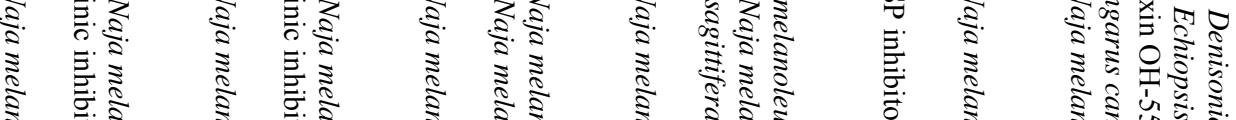

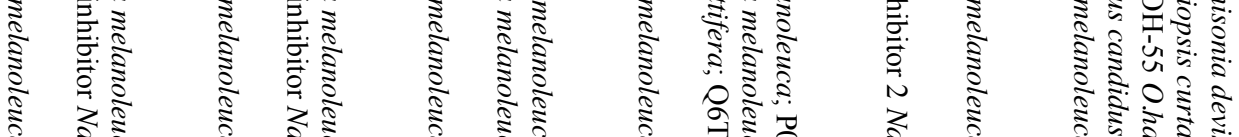

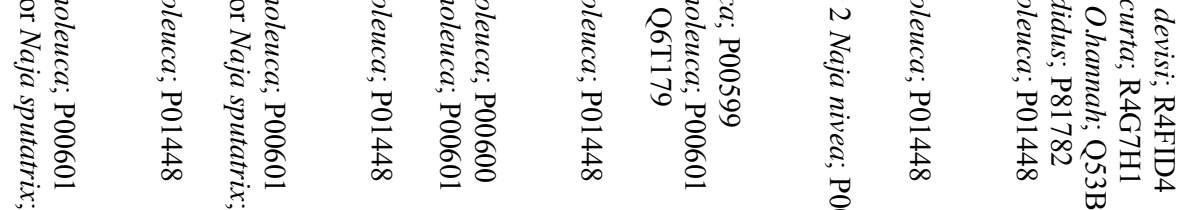

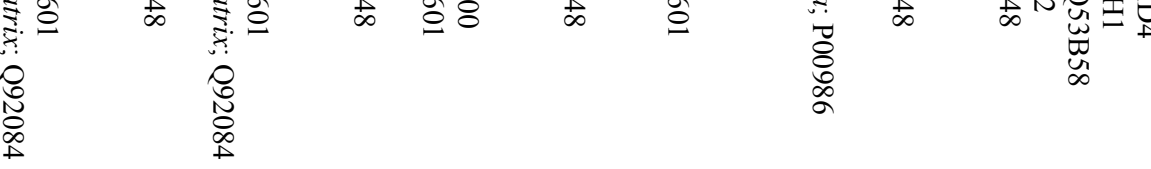

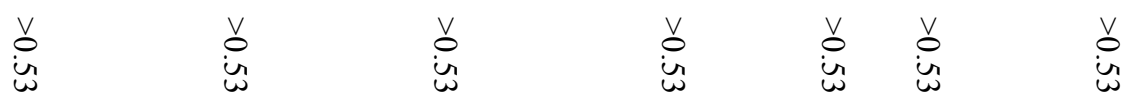

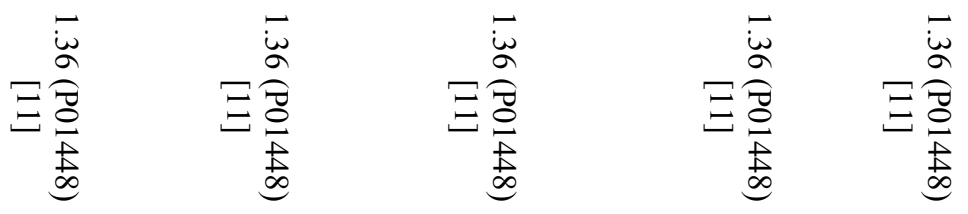

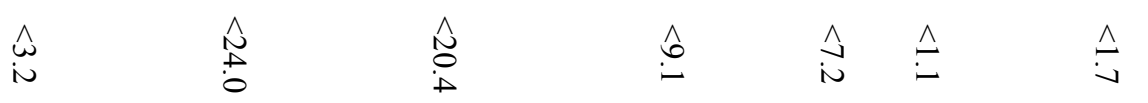

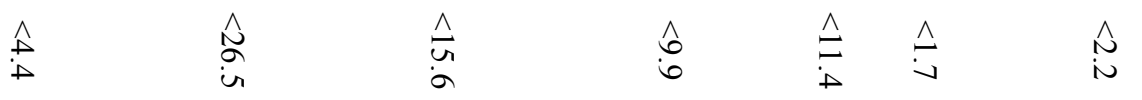




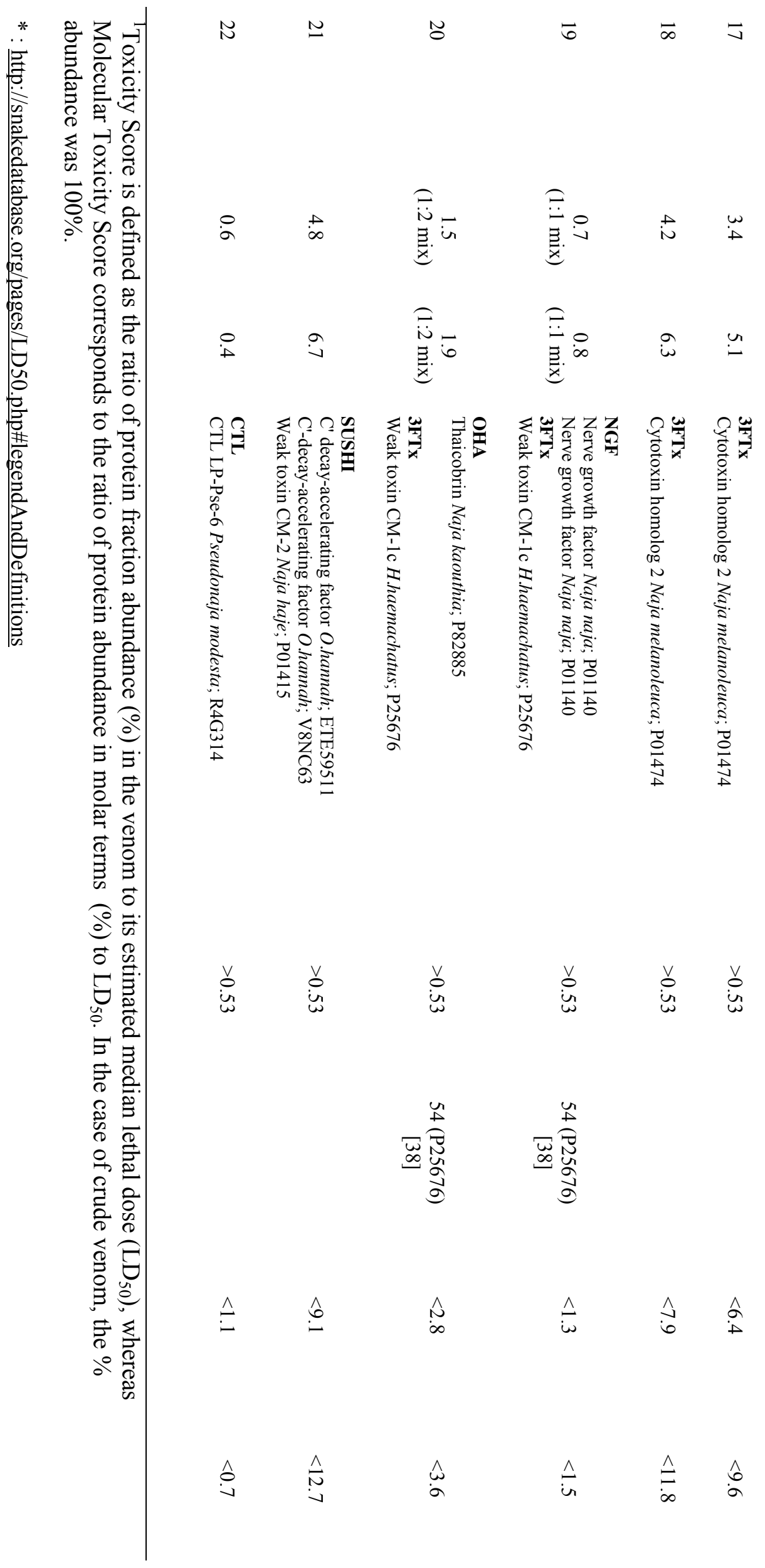


Figure 1

Click here to download high resolution image

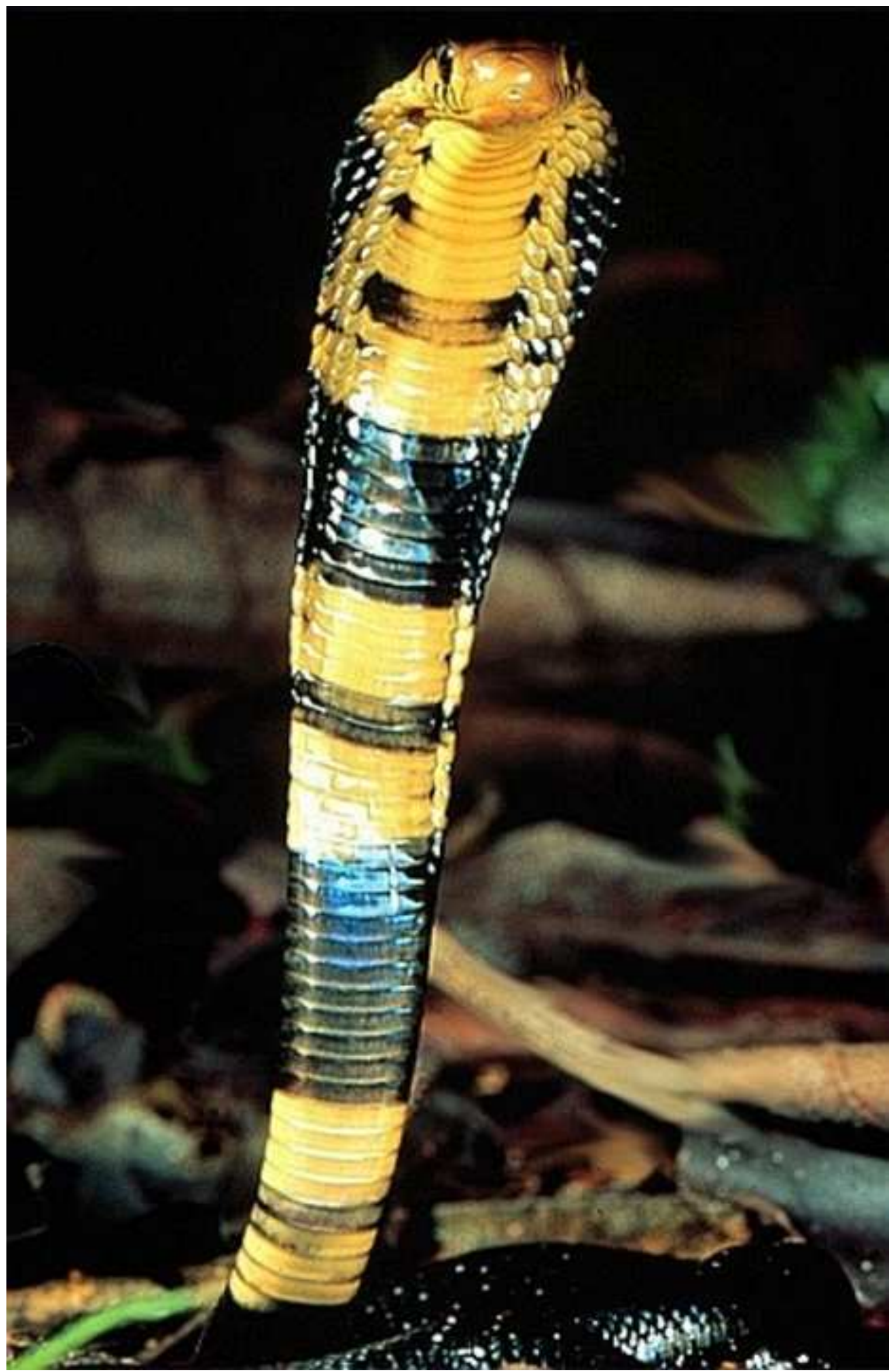




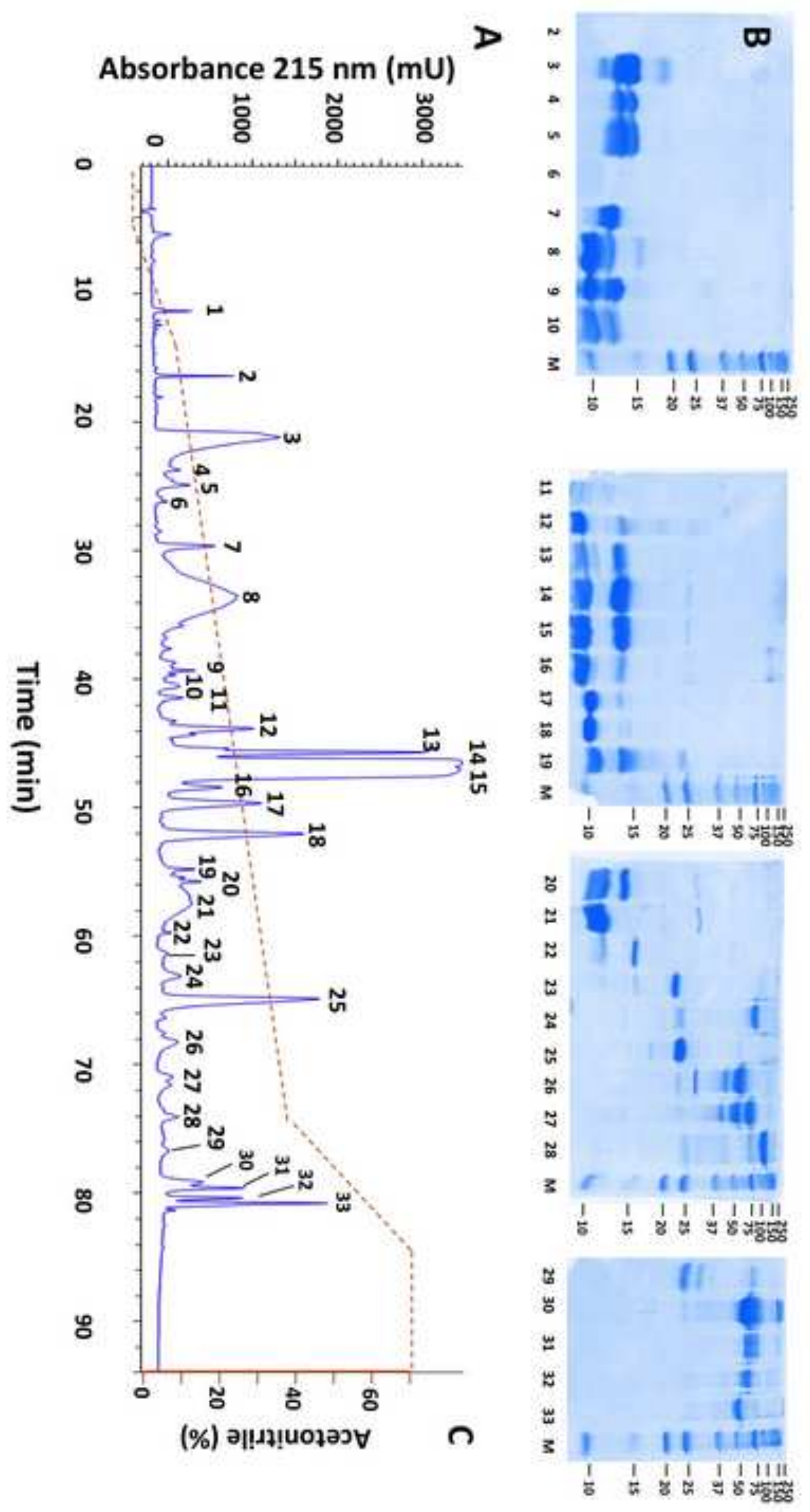




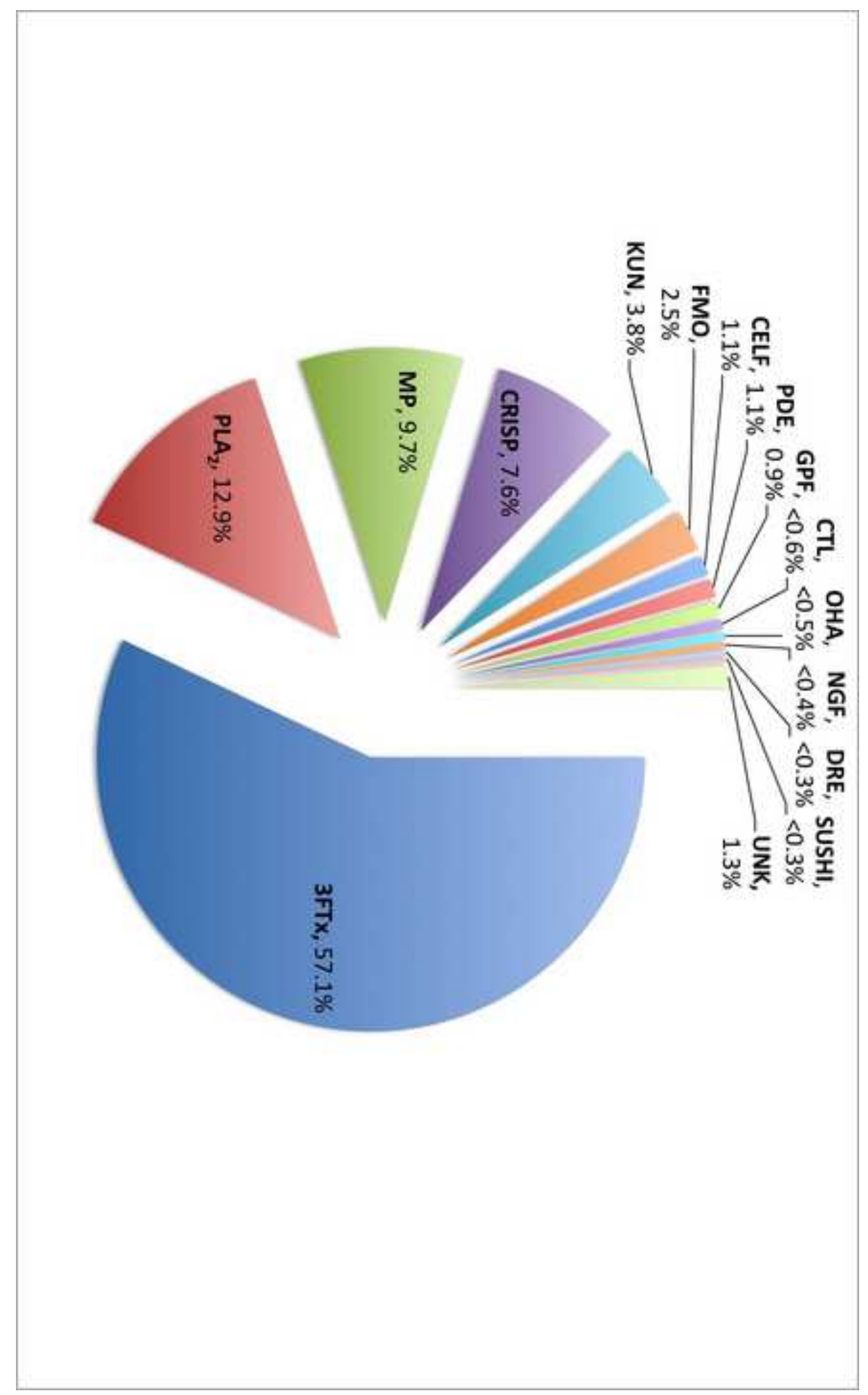

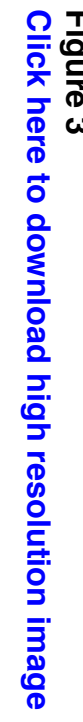




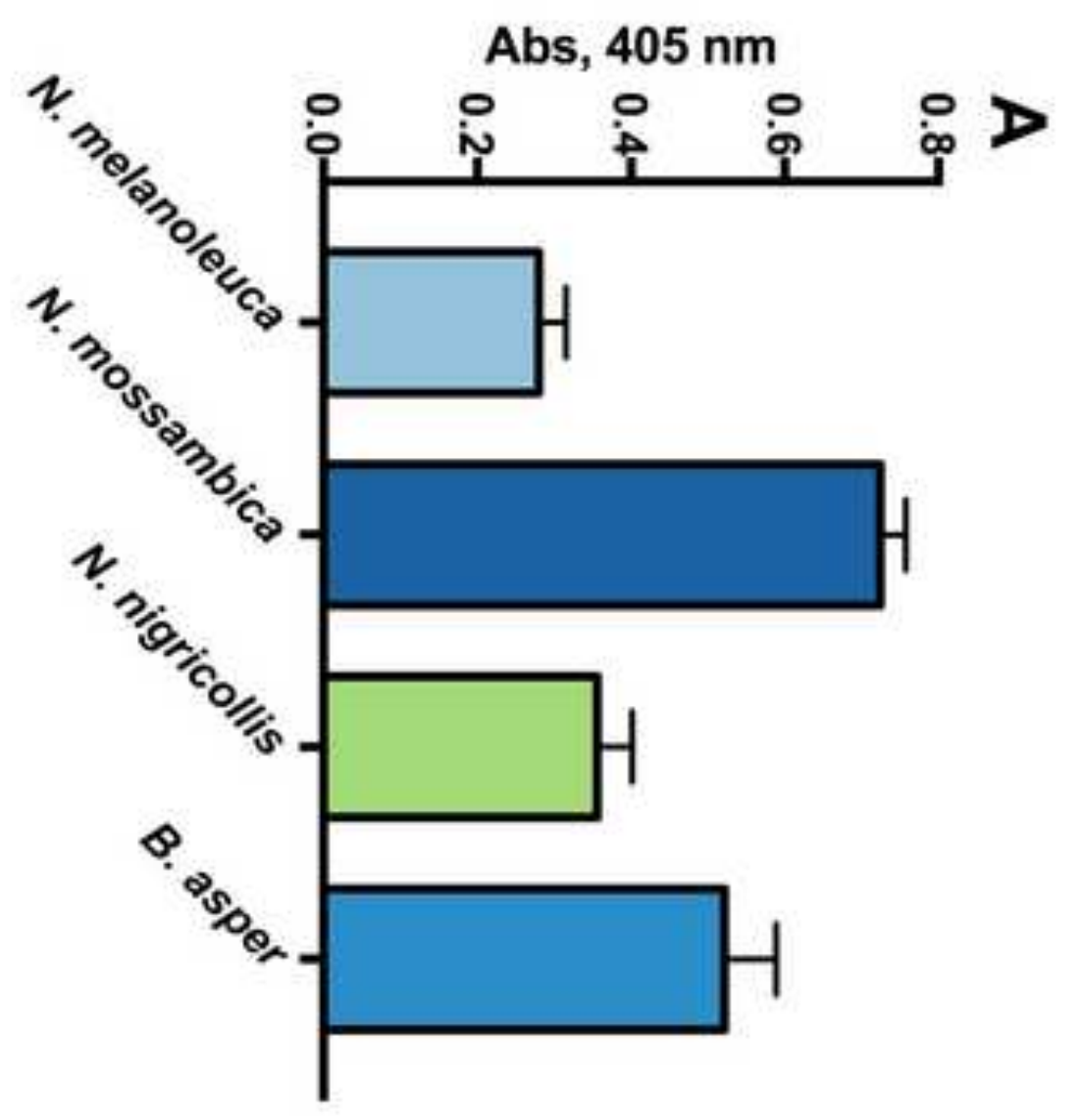

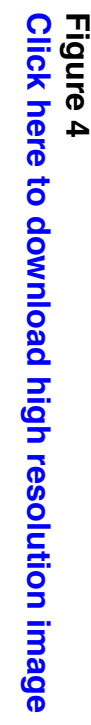

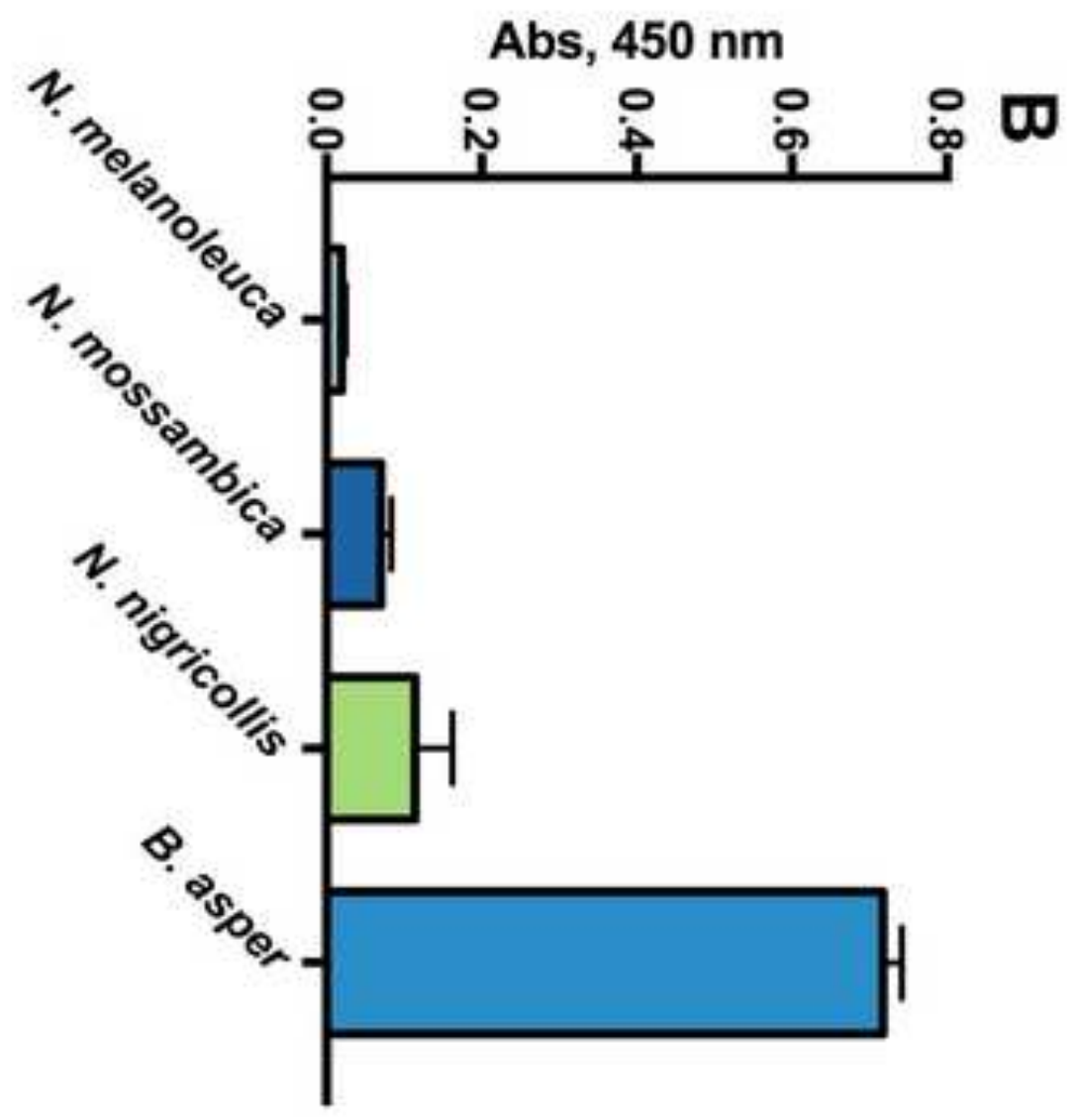




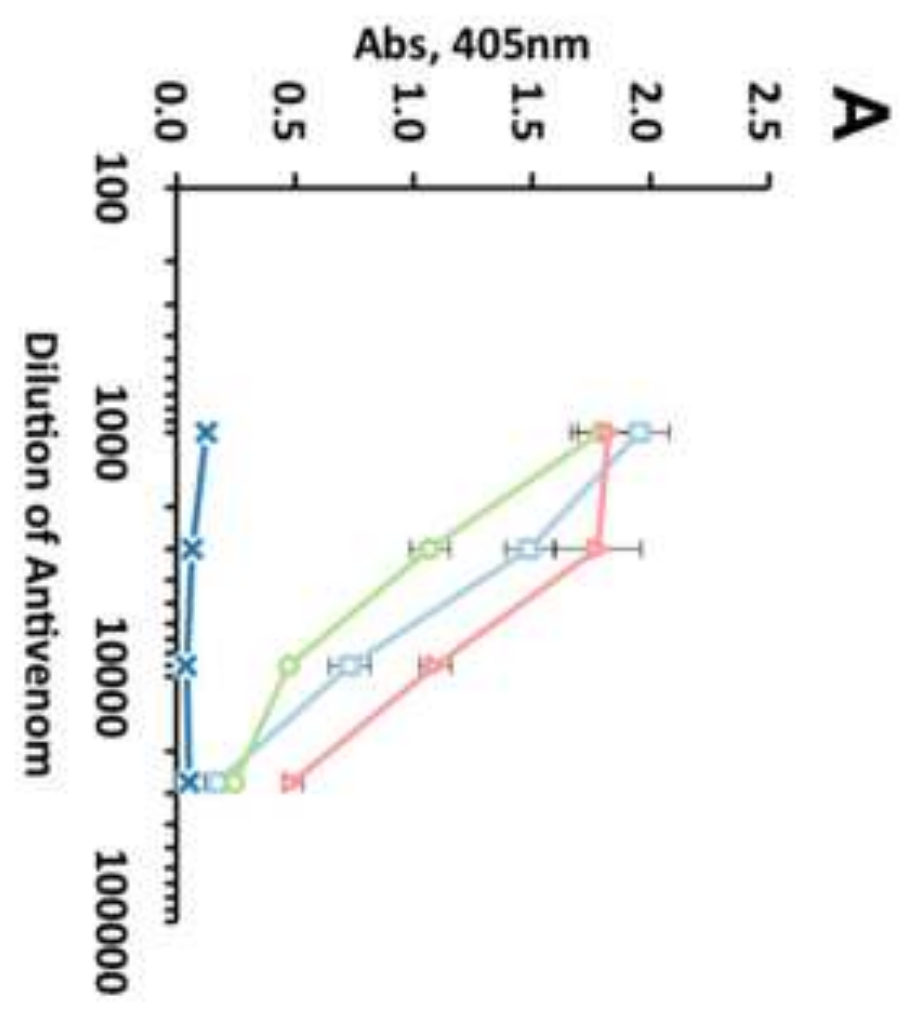

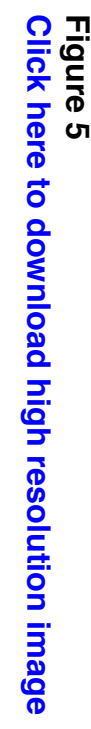

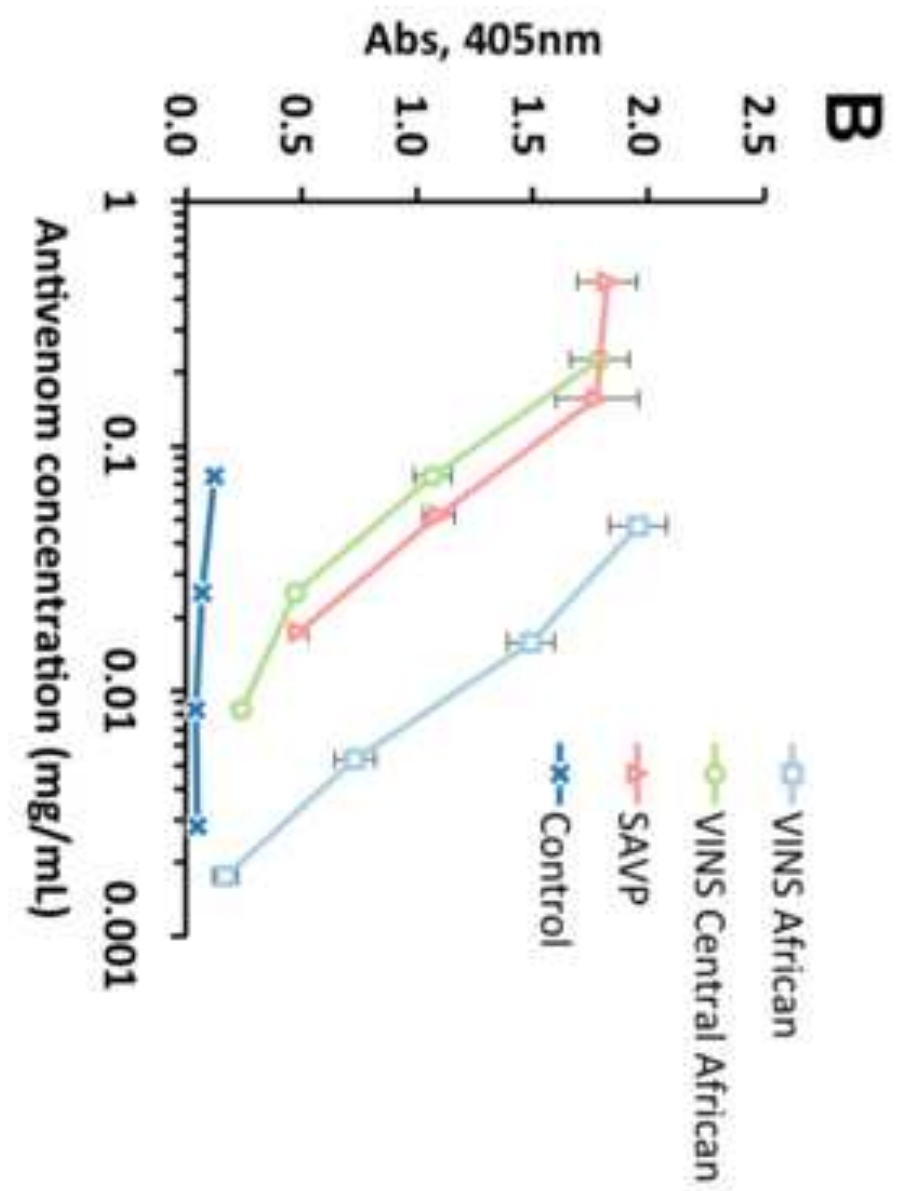




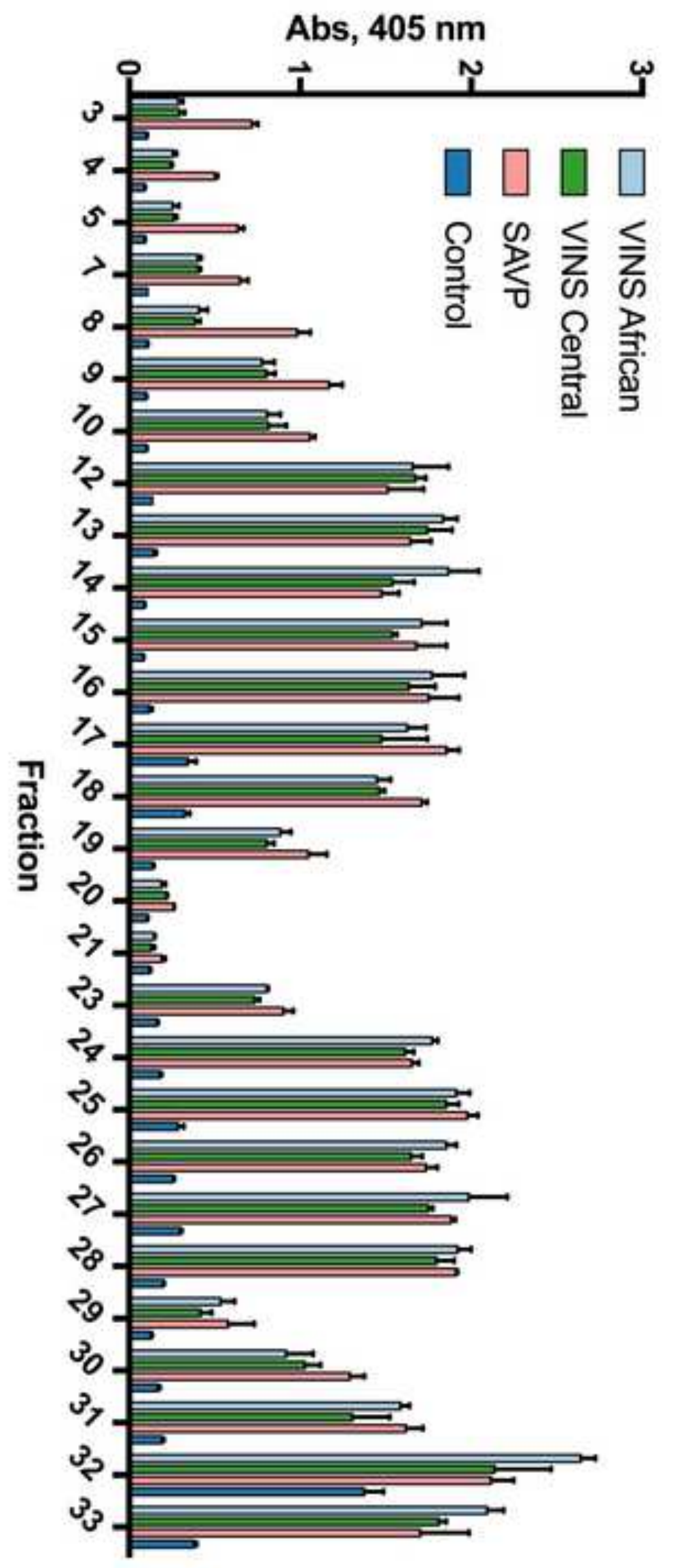

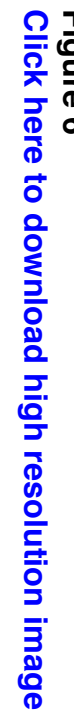


${ }^{*}$ Conflict of Interest

Click here to download Conflict of Interest: Conflict of interest statement.docx 